\title{
Reliability analysis of stability against piping and sliding in diversion dams, considering four cutoff wall configurations
}

\author{
Ali Akbar Hekmatzadeh ${ }^{\text {a }},{ }^{1}$, Farshad Zarei ${ }^{\text {a }}$, Ali Johari ${ }^{\text {a }}$, Ali Torabi Haghighi ${ }^{\text {b }}$ \\ a- Department of Civil and Environmental Engineering, Shiraz University of Technology, Po. Box \\ 71555-313, Shiraz, Iran, email: hekmatzadeh@sutech.ac.ir, \\ $b$ - Water Resources and Environmental Engineering Research Group, University of Oulu, PO Box 4300, \\ FIN-90014, Finland
}

\begin{abstract}
The stability against piping and sliding, which is subject to numerous sources of uncertainty, is of great importance in the design of diversion dams. In this study, the performance of four cutoff wall configurations, including a single wall and two walls with half the length of the single wall, was evaluated stochastically using the random finite element method. The Cholesky decomposition technique in conjunction with three types of Auto-Correlation Function (ACF) was employed to generate numerous random fields. The results indicate that the probabilities of failure related to different cutoff wall configurations are similar, considering isotropic hydraulic conductivity. However, there are noticeable differences between the probabilities of failure of these configurations in anisotropic situations. Moreover, the use of a single cutoff wall on the upstream face of an impervious blanket provides the lowest probability of failure for piping. In addition, the exponential ACF ends up with greater exit hydraulic gradients than the second-order Markov and binary noise ACFs. In addition, the sliding stability of the ordinary and earthquake load combinations was examined stochastically using random field theory and Monte Carlo Simulation (MCS). The probability of failure appears to increase with an increase in the autocorrelation distance.
\end{abstract}

keyword: Probability of failure; Diversion dam; Piping; Sliding stability; Random finite element method; Auto-correlation function

Corresponding author. Tel.: +98 71 37277656, Mobile: +98 9177140175, Fax: +98 71 37277656. Email address: hekmatzadeh@sutech.ac.ir \& hekmatzadeh@yahoo.com (A. A. Hekmatzadeh). 


\section{Nomenclature}

$\mathrm{K}_{\mathrm{x}} \quad$ Hydraulic conductivity along $\mathrm{x}$ direction

$\mathrm{K}_{\mathrm{z}} \quad$ Hydraulic conductivity along $\mathrm{z}$ direction

h Total head

$\mu_{\mathrm{K}} \quad$ Mean of hydraulic conductivity

$\sigma_{\mathrm{K}} \quad$ Standard deviation of hydraulic conductivity

$\mu_{\mathrm{InK}} \quad$ Mean of logarithmic hydraulic conductivity

$\sigma_{\operatorname{lnK}} \quad$ Standard deviation of logarithmic hydraulic conductivity

COV Coefficient of variation of hydraulic conductivity

$\tau_{\mathrm{x}_{\mathrm{ij}}} \quad$ Distance between the centroid of the $\mathrm{i}^{\text {th }}$ and $\mathrm{j}^{\text {th }}$ elements in the horizontal direction

$\tau_{z_{\mathrm{ij}}} \quad$ Distance between the centroid of the $\mathrm{i}^{\text {th }}$ and $\mathrm{j}^{\text {th }}$ elements in the vertical direction

$\delta_{\mathrm{h}} \quad$ Horizontal autocorrelation distance of the hydraulic conductivity

$\delta_{\mathrm{v}} \quad$ Vertical autocorrelation distance of the hydraulic conductivity

$\rho\left(\tau_{\mathrm{x}_{\mathrm{ij}}}, \tau_{\mathrm{z}_{\mathrm{ij}}}\right) \quad$ Auto-correlation coefficient between the centroids of elements

C Auto-correlation matrix

$\mathrm{n}_{\mathrm{e}} \quad$ Number of random field elements

L Lower triangular matrix

$\mathrm{G}_{\mathrm{i}} \quad$ Standard Gaussian random field

$\mathrm{Z}_{\mathrm{i}} \quad$ An indicator of standard normal distribution

$\mathrm{K}_{\mathrm{x}_{\mathrm{i}}} \quad$ Hydraulic conductivity assigned to the $\mathrm{i}^{\text {th }}$ element in the $\mathrm{x}$ direction

$\mathrm{K}_{\mathrm{z}_{\mathrm{i}}} \quad$ Hydraulic conductivity assigned to the $\mathrm{i}^{\text {th }}$ element in the $\mathrm{z}$ direction

SF Safety factor

$\mathrm{g}(\mathrm{s}) \quad$ Performance function

E Expected value

$\beta \quad$ Reliability index

$\mathrm{P}_{\text {failure }} \quad$ Probability of failure

$\Phi \quad$ Standard normal cumulative distribution function

$\mathrm{SF}_{\text {piping }} \quad$ Safety factor against piping

$i_{c r} \quad$ Critical hydraulic gradient

$\mathrm{i}_{\text {exit }} \quad$ Exit hydraulic gradient

$\gamma^{\prime} \quad$ Submerged unit weight of soil particles

$\gamma_{w} \quad$ Unit weight of water

$\mathrm{SF}_{\text {sliding }} \quad$ Safety factor against sliding

$\mathrm{c}_{\mathrm{i}} \quad$ Unit shearing strength

$\phi_{\mathrm{i}} \quad$ Angle of shearing resistance

$\mathrm{A}_{\mathrm{i}} \quad$ Area of the plane of sliding

$\mathrm{W}_{\mathrm{i}} \quad$ Weight of the dam

$\gamma_{\mathrm{s}}^{\prime} \quad$ Submerged unit weight of sediment

$\phi_{\mathrm{s}} \quad$ Friction angle of sediment

$\alpha_{\mathrm{h}} \quad$ Horizontal seismic coefficient 


$\begin{array}{cl}\alpha_{\mathrm{v}} & \text { Vertical seismic coefficient } \\ \mathrm{H} & \text { Dam height } \\ \mathrm{C}_{\mathrm{e}} & \text { Dimensionless hydrodynamic factor } \\ \mathrm{R}^{2} & \text { Correlation coefficient } \\ \alpha & \text { Indicator of skewness } \\ \omega & \text { Constant of skew normal distribution } \\ \xi & \text { Constant of skew normal distribution } \\ \mu_{\mathrm{sk}} & \text { Mean of skew normal distribution } \\ \sigma_{\mathrm{sk}} & \text { Standard deviation of skew normal distribution } \\ \mathrm{S} & \text { Skewness } \\ \lambda & \text { A constant }\end{array}$

\section{Introduction}

Diversion dams are important hydraulic structures that are usually built on the cross-section of alluvial rivers to raise the level of water in the river [1]. These hydraulic structures are usually of low height and therefore have small reservoirs. The essential criteria governing the design of diversion dams are the concerns of stability against internal erosion and sliding [1-5].

Internal erosion in the soil foundation of dams may be initiated by backward erosion. As a result, a continuous tunnel, also called a pipe, is formed between the upstream and downstream sides of the dam, causing dam failure [6-10]. To decrease the risk of piping, an upstream impervious blanket and cutoff wall are usually designed to increase the creep length of seepage flow [11]. More importantly, sliding due to active forces, including the earthquake and hydraulic forces, is possibly the predominant reason for the failure of diversion dams [1,3]. The prevailing stability analysis of diversion dams is usually based on the deterministic methods, mainly reported in the United States Bureau of Reclamation (USBR) criteria and the other design books $[1,3,12]$. However, there is uncertainty associated with the soil properties $[13,14]$, earthquake components, and active forces exerted on dams [5,15], leading to uncertainty in the safety factor. This leads to 
a question of how safe the newly designed or existing diversion dam is. Therefore, the probabilistic analysis of the safety factor is essential to estimate the possibility of dam failure under different operating conditions.

Recently, probabilistic analysis using the random field theory has been employed in different fields of engineering, including geotechnical, structural, and water engineering. Several types of stochastic slope stability analyses have been conducted by Griffiths et al. [16], Lo and Leung [17] and Ji et al. [18,19]. Do et al. [20] considered random field for the Young's modulus and body force in the analysis of structures.

Considering seepage analysis, Griffiths and Fenton [21] considered the effect of spatial variability of hydraulic conductivity to examine seepage flow underneath a retaining structure. The finite element method in conjunction with the random field theory was applied in their study. Cho [22] performed probabilistic seepage analyses beneath an embankment dam using the random finite element method. Two types of soil layer were assumed for the dam foundation in that study, in which the permeability followed lognormal distributions. More studies can be found in Tan et al. [23], Srivastava et al. [24], Ahmed [25,26], and Griffiths and Fenton [27-29]. In terms of dam sliding, the effect of uncertainty in the cohesive strength of the interface between a concrete dam and a rock foundation was examined by Krounis et al. [5].

To the best of the author's knowledge, no article has been found that is focused on the probabilistic stability analysis of diversion dams. In the deterministic design procedure, the provision of an adequate creep length of water beneath the dam is a key parameter for decreasing the exit hydraulic gradient. Therefore, there is no difference between the implication of a single cutoff wall or the construction of two cutoff walls at different locations, where the height of each wall is equal to half of the height of the single wall [1-4]. Although several articles have been 
found concerning probabilistic seepage analysis, the probabilistic assessment of different cutoff wall configurations has not yet been investigated [21-26].

Moreover, the anisotropy of soil hydraulic conductivity throughout history may stem from alluvial sedimentation. Little attention has been paid to the anisotropy of soil permeability in the literature [21,22,27-29]. In addition, few studies have explored the influence of several AutoCorrelation Functions (ACFs) in the random field generation [30,31]. Regarding sliding stability, a small number of investigations have concentrated on the probabilistic analysis of the safety factor against sliding [5]. The probabilistic approach has not yet been completely applied to dam safety guidelines, which is crucial to decision makers.

The main motivation of this study is to perform a probabilistic analysis of the stability of a diversion dam against piping and sliding. For this purpose, the random finite element method has been employed to perform probabilistic seepage analysis in two dimensions. The Cholesky decomposition technique is used to generate random hydraulic conductivity, considering exponential second-order Markov and binary noise two-dimensional auto-correlation functions. Moreover, four configurations of cutoff walls are considered in the probabilistic analyses. By the implementation of stochastic analysis on the exit hydraulic gradient, the best configuration of the cutoff wall has been determined. In addition, the stability of the dam against sliding is also examined stochastically using the MCS in combination with random field discretization. The ordinary and earthquake load combinations are considered in the stochastic analysis of sliding stability. Fig. 1 shows the flowchart of the procedure used in this study.

\section{Seepage analysis}


The seepage flow beneath a diversion dam can be modeled using the mass balance relationship. Assuming Darcy's law, the governing equation of seepage flow is written as follows:

$$
\frac{\partial}{\partial \mathbf{x}}\left(\mathrm{K}_{\mathrm{x}} \frac{\partial \mathrm{h}}{\partial \mathrm{x}}\right)+\frac{\partial}{\partial \mathrm{z}}\left(\mathrm{K}_{\mathrm{z}} \frac{\partial \mathrm{h}}{\partial \mathbf{z}}\right)=0
$$

where $K_{x}$ and $K_{z}$ stand for the hydraulic conductivity of the soil along the $\mathrm{x}$ and $\mathrm{z}$ directions, respectively, and $\mathrm{h}$ is the water head [22]. This equation can be solved numerically using the Finite Element Method (FEM). The detailed formulation of relevant algebraic equations obtained by FEM can be followed in Reddy (1993) [32].

\section{Random field theory}

The properties of natural soil such as hydraulic conductivity have spatial variability because

of the geological formation of the soil [31,34]. The spatial variability of hydraulic conductivity can be described by means of random field theory. Therefore, an appropriate Probability Density Function (PDF) and a correlation structure or ACF are required. The lognormal distribution is an appropriate tool to model the variability of soil properties, including the hydraulic conductivity $[21,24]$. The mean and standard deviation $\left(\mu_{\ln K}\right.$ and $\left.\sigma_{\ln K}\right)$ of this distribution are stated as Eqs. 2 and 3, respectively.

$$
\begin{aligned}
& \mu_{\mathrm{lnK}}=\ln \left(\mu_{\mathrm{K}}\right)-\frac{1}{2} \sigma_{\ln \mathrm{K}}^{2} \\
& \sigma_{\mathrm{lnK}}=\sqrt{\ln \left(1+\frac{\sigma_{\mathrm{K}}^{2}}{\mu_{\mathrm{K}}^{2}}\right)}=\sqrt{\ln \left(1+\mathrm{COV}^{2}\right)}
\end{aligned}
$$

where $\mu_{\mathrm{K}}$ and $\sigma_{\mathrm{K}}$ are the mean and standard deviation of hydraulic conductivity. There are numerous ACFs to describe the degree of correlation between two points irrespective of their 
global coordinate $[30,31]$. The most applied ACF used to illustrate the spatial variability of soil characteristics is the Exponential Auto-Correlation Function (E-ACF) [35-37], which is given by:

$$
\rho\left(\tau_{x_{i j}}, \tau_{z_{i j}}\right)=\exp \left(-\frac{\tau_{x_{i j}}}{\delta_{h}}-\frac{\tau_{z_{i j}}}{\delta_{v}}\right)=\exp \left(-\frac{\left|x_{\mathrm{i}}-x_{j}\right|}{\delta_{h}}-\frac{\left|z_{\mathrm{i}}-z_{j}\right|}{\delta_{v}}\right)
$$

where $\tau_{\mathrm{x}_{\mathrm{ij}}}=\left|\mathrm{x}_{\mathrm{i}}-\mathrm{x}_{\mathrm{j}}\right|$ and $\tau_{\mathrm{z}_{\mathrm{ij}}}=\left|\mathrm{z}_{\mathrm{i}}-\mathrm{z}_{\mathrm{j}}\right|$ are the absolute distances between two points in the horizontal and vertical directions, respectively. The parameters $\delta_{\mathrm{h}}$ and $\delta_{\mathrm{v}}$ represent the horizontal and vertical autocorrelation distances of hydraulic conductivity, respectively.

To investigate the influence of different ACFs, the Second-Order Markov and the Binary Noise Auto-Correlation Functions (SOM-ACF and BN-ACF) [31,32] were also employed, written by Eqs. 5 and 6, respectively.

$$
\begin{aligned}
& \rho\left(\tau_{x_{i j}}, \tau_{z_{i j}}\right)=\exp \left(-4\left[\frac{\left|x_{i}-x_{j}\right|}{\delta_{h}}+\frac{\left|z_{i}-z_{j}\right|}{\delta_{v}}\right]\right)\left(1+\frac{4\left|x_{i}-x_{j}\right|}{\delta_{h}}\right)\left(1+\frac{4\left|z_{i}-z_{j}\right|}{\delta_{v}}\right) \\
& \rho\left(\tau_{x_{i j}}, \tau_{z_{i j}}\right)=\left\{\begin{array}{lc}
\left(1-\frac{\left|x_{i}-x_{j}\right|}{\delta_{h}}\right)\left(1-\frac{\left|z_{i}-z_{j}\right|}{\delta_{v}}\right) & \text { for } \tau_{x_{i j}}<\delta_{h} \text { and } \tau_{z_{i j}}<\delta_{v} \\
0 & \text { otherwise }
\end{array}\right.
\end{aligned}
$$

Considering finite element mesh, the following auto-correlation matrix, $\mathrm{C}$, is constructed for the whole domain:

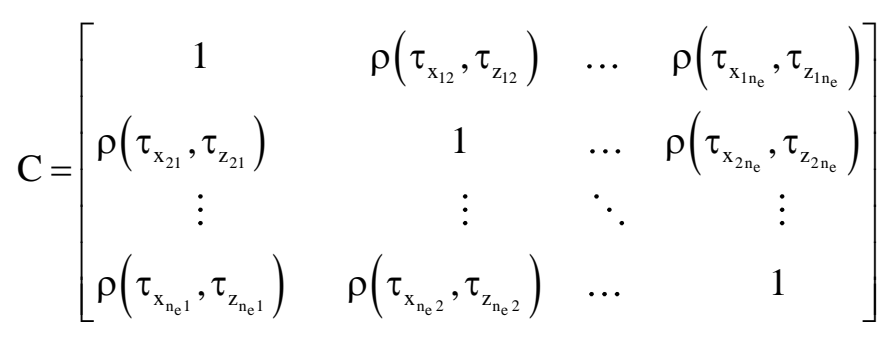


where $\rho\left(\tau_{x_{\mathrm{ij}}}, \tau_{z_{\mathrm{ij}}}\right)$ indicates the auto-correlation coefficient between the centroids of elements. The parameters $\tau_{\mathrm{x}_{\mathrm{ij}}}$ and $\tau_{\mathrm{z}_{\mathrm{ij}}}$ indicate the distances between the centroid of the $\mathrm{i}^{\text {th }}$ and the $\mathrm{j}^{\text {th }}$ elements. In this study, the Cholesky decomposition method $[24,30,36]$ was used to generate random values of hydraulic conductivity. Accordingly, the abovementioned matrix is decomposed into the product of a lower triangular matrix, L, and its transpose (Eq. 8).

$$
\mathrm{LL}^{\mathrm{T}}=\mathrm{C}
$$

Regarding matrix L, the standard Gaussian random field can be attained using Eq. 9:

$$
\mathrm{G}_{\mathrm{i}}=\sum_{\mathrm{j}=1}^{\mathrm{i}} \mathrm{L}_{\mathrm{ij}} \mathrm{Z}_{\mathrm{j}}, \quad \mathrm{i}=1,2,3, \ldots, \mathrm{n}
$$

In this equation, $G_{i}$ means the standard Gaussian random field, and $Z_{j}$ follows the standard normal distribution ( $\mu=0$ and $\sigma=1$ ). Finally, the values of the hydraulic conductivity along the $\mathrm{x}$ and $\mathrm{y}$ directions $\left(\mathrm{K}_{\mathrm{x}_{\mathrm{i}}}, \mathrm{K}_{\mathrm{z}_{\mathrm{i}}}\right.$ ) for each element are estimated as follows:

$$
\begin{aligned}
& \mathrm{K}_{\mathrm{x}_{\mathrm{i}}}=\exp \left\{\mu_{\mathrm{lnK}_{\mathrm{x}}}+\sigma_{\ln \mathrm{K}_{\mathrm{x}}} \mathrm{G}_{\mathrm{i}}\right\} \\
& \mathrm{K}_{\mathrm{z}_{\mathrm{i}}}=\exp \left\{\mu_{\ln _{\mathrm{z}}}+\sigma_{\ln _{\mathrm{z}}} \mathrm{G}_{\mathrm{i}}\right\}
\end{aligned}
$$

A similar procedure was employed to generate stochastic shear strength parameters, $\mathrm{c}$ and $\phi$, at the sliding plane between the dam and its foundation. However, one-dimensional E-ACF (Eq. 12) was applied instead of Eq. 4.

$$
\rho\left(\tau_{\mathrm{x}_{\mathrm{ij}}}\right)=\exp \left(-\frac{\tau_{\mathrm{x}_{\mathrm{ij}}}}{\delta_{\mathrm{h}}}\right)=\exp \left(-\frac{\left|\mathrm{x}_{\mathrm{i}}-\mathrm{x}_{\mathrm{j}}\right|}{\delta_{\mathrm{h}}}\right)
$$




\section{Monte Carlo Simulation}

Monte Carlo Simulation is a robust universal method for determining the probability density of a performance function. This method consists of generating random numbers for independent parameters regarding their PDF, estimating the dependent function for each generated set, and finally repeating this process adequately until the probability distribution of the performance function is reached [38-41].

The operating state of a diversion dam can be described by a performance function $(\mathrm{g}(\mathrm{s}))$. This function for sliding stability is stated as:

$$
\mathrm{g}(\mathrm{s})=\mathrm{SF}(\mathrm{s})-1
$$

where $\mathrm{SF}(\mathrm{s})$ can be the safety factor against piping or sliding, and s represents the vector of random variables. If $g(s)>0$, the dam will be stable; otherwise, the dam will not be safe $[42,43]$. It is possible to obtain the probability distribution of $\mathrm{g}(\mathrm{s})$ using MCS, and then, the reliability index is estimated using Eq. 14.

$$
\beta=\frac{E[g(s)]}{\sigma[g(s)]}
$$

where $\mathrm{E}$ and $\sigma$ stand for the mean and standard deviation of the performance function. The above equation is accurate when the performance function is normally distributed. If the performance function not normally distributed, the equation gives an approximation [42,43]. Once the PDF is not specified, the probability of failure can be stated as a function of the reliability index:

$$
\mathrm{P}_{\text {failure }}=\Phi(-\beta)=1-\Phi(\beta)
$$


In this equation, $\Phi$ is the standard normal Cumulative Distribution Function (CDF) [44]. Eq. 15 is accurate when the variables follow the normal distribution and the performance function is linear; otherwise, the equation is an approximation [45].

\section{Example of diversion dam}

In this article, a diversion dam with a height of $6 \mathrm{~m}$ was assumed according to Fig. 2. Based on the deterministic stability criteria $[1,3,12]$, the crest width and the base width of the diversion dam were estimated to be $0.5 \mathrm{~m}$ and $7 \mathrm{~m}$, respectively. An 8-meter-long stilling basin with a thickness of $1 \mathrm{~m}$ was considered at the dam toe for the purpose of energy dissipation during a flood. Moreover, a combination of upstream blanket and cutoff wall is assumed to reduce the exit hydraulic gradient. Therefore, a blanket with a length of $10 \mathrm{~m}$ was assumed at the upstream face of the dam. Four cutoff wall configurations with equal creep length were considered. A 6-meterhigh cutoff wall was assumed for configurations 1 and 2 at different locations, whereas two walls of a height of $3 \mathrm{~m}$ were considered for configurations 3 and 4 (see Fig. 2). The finite element mesh with reference to configuration 1 is depicted in Fig. 3.

Regarding mesh size, the random field can be discretized into finite control points, where the hydraulic conductivity is considered a random variable. The discretization size of the random field can be smaller than the finite element size. The hydraulic conductivity at other locations can be estimated using the method of interpolated autocorrelations $[45,46]$. Consequently, a smaller autocorrelation matrix is obtained, leading to a more efficient solution. However, this procedure

may reduce the accuracy of the random finite element solution, particularly when several cutoff wall configurations are supposed to be compared. Therefore, the same mesh size is used for both finite element and random field in this study to maintain the precision. 


\subsection{Safety factor against internal erosion and sliding}

Internal erosion in a diversion dam is a great concern that should be considered in the design stage. The safety factor against piping is defined by the ratio of the critical hydraulic gradient to the exit hydraulic gradient (Eq. 16).

$$
\mathrm{SF}_{\text {piping }}=\frac{\mathrm{i}_{\mathrm{cr}}}{\mathrm{i}_{\text {exit }}}=\frac{\gamma^{\prime}}{\gamma_{\mathrm{w}} \mathrm{i}_{\text {exit }}}
$$

where $\gamma^{\prime}$ is the submerged unit weight of soil particles, $\gamma_{w}$ is the unit weight of water, and $i_{c r}$ and $\mathrm{i}_{\text {exit }}$ represent the critical hydraulic gradient and the output gradient at the toe of the stilling basin, respectively [2]. In this study, the deterministic safety factor against piping is set to one [47].

The dam stability against sliding is one of the most important criteria for the design of diversion dams. The sliding stability is a function of soil shear resistance parameters in addition to the active forces. In this study, two common patterns of loading, called ordinary and earthquake load combinations, were considered. The sediment and hydrostatic pressure as well as the uplift force were considered in the ordinary load pattern. Regarding earthquake load combinations, the earthquake inertia force and its corresponding hydrodynamic pressure were also added to the abovementioned active forces. The safety factor against sliding is expressed below $[1,3]$ :

$$
\mathrm{SF}_{\text {sliding }}=\frac{\sum\left(\mathrm{c}_{\mathrm{i}} \mathrm{A}_{\mathrm{i}}+\left(\mathrm{W}_{\mathrm{i}}-\mathrm{W}_{\mathrm{i}} \alpha_{\mathrm{v}}-\mathrm{U}_{\mathrm{i}}\right) \tan \phi_{\mathrm{i}}\right)}{\frac{1}{2} \gamma_{\mathrm{w}} \mathrm{H}^{2}+\frac{1}{2}\left(\frac{1-\sin \phi_{\mathrm{s}}}{1+\sin \phi_{\mathrm{s}}}\right) \gamma_{\mathrm{s}}^{\prime} \mathrm{H}^{2}+\mathrm{W} \alpha_{\mathrm{h}}+0.726 \mathrm{C}_{\mathrm{e}} \alpha_{\mathrm{h}} \gamma_{\mathrm{w}} \mathrm{H}^{2}}
$$

In the above equation, $\mathrm{H}$ is the dam height, $\mathrm{W}_{\mathrm{i}}$ stands for the weight of the $\mathrm{i}^{\text {th }}$ slice of the dam, and $\phi_{\mathrm{s}}$ and $\gamma_{\mathrm{s}}^{\prime}$ are the friction angle and submerged unit weight of the sediment, respectively. The 
horizontal and vertical seismic coefficients are identified by $\alpha_{h}$ and $\alpha_{v}$, respectively. $C_{e}$ is the dimensionless hydrodynamic factor that is equal to 0.73 [3]. $\mathrm{C}_{\mathrm{i}}$ and $\phi_{\mathrm{i}}$ are the shear resistance parameters of the $\mathrm{i}^{\text {th }}$ slice of the sliding surface. The area of each segment of contact surface is represented by $A_{\mathrm{i}}$. In line with Novak et al. (2007) [3], the safety factors against sliding under the ordinary and earthquake load combinations are three and one, respectively.

The equations for the safety factor (Eqs. 16 and 17) mentioned above contain two groups of parameters. The first group is deterministic, including dam weight and its height. These parameters and their corresponding values are given in Table 1 . The second parameters follow a probability distribution such as the lognormal, the truncated normal, and the exponential distributions due to their variability nature. The hydraulic conductivity of the soil particles complies with the lognormal distribution (Table 2). The soil mechanical properties such as friction angle and shear resistance are described by the truncated normal distribution, reported in Table 3 .

The exponential distribution was employed to specify the stochastic coefficients of the earthquake, given in Table 4. Both isotropic and anisotropic conditions were presumed for hydraulic conductivity with different values of COV and autocorrelation distance. Moreover, the mean of the earthquake coefficient, mentioned in Table 4, was attained based on the Iranian code of practice for seismic resistant design, also called standard 2800.

\section{Results and discussion}

\subsection{Stochastic flow net}

To assess the accuracy of the finite element program presented, the seepage results obtained for the cutoff wall configurations 1 to 4 (see Fig. 2) were compared to those of a commercial seepage 
analysis software, SEEP/W. The values of seepage flow rates computed by the SEEP/W and the presented program are listed in Table 5. For all configurations, the estimations of the presented finite element program are identical to those of SEEP/W, indicating the high accuracy of the program. Figs. 4 and 5 show the spatial variability of hydraulic conductivity, which stems from the application of random field theory concerning the configuration 1 . The coefficient of variation in these figures is 0.5. Nevertheless, their autocorrelation distances are different. The autocorrelation distance is $1 \mathrm{~m}$ in Fig. 4, whereas the autocorrelation distance is $10 \mathrm{~m}$ in Fig. 5. As shown, the higher the autocorrelation distance is, the more homogeneous the obtained soil realization will be. The stochastic equipotential lines of several random realizations regarding the four configurations are displayed in Fig. 6. The equipotential lines deviate in different directions, implying a variable exit hydraulic gradient in different locations.

\subsection{Probabilistic analysis of different configurations of the cutoff wall.}

The effects of spatial variability in hydraulic conductivity on the reliability of piping for the abovementioned diversion dam with different cutoff wall configurations are illustrated in Figs. 7 to 10 . For every situation, accurate statistical results were obtained from the generation of 15000 random field realizations. Four scenarios of soil variability were taken into consideration regarding isotropic and anisotropic random hydraulic conductivity along the $\mathrm{x}$ and $\mathrm{z}$ directions, i.e., $\mathrm{K}_{\mathrm{x}}$ and $\mathrm{K}_{\mathrm{z}}$, respectively, as follows:

- Scenario 1: $\mathrm{K}_{\mathrm{x}}$ was generated using random field theory, while $\mathrm{K}_{\mathrm{z}}=\mathrm{K}_{\mathrm{x}}$ was always maintained (see Fig. 7). Accordingly, slightly lower probabilities of failure are obtained for the configuration 1 , where the cutoff wall is located on the upstream face of the impervious 
blanket. However, the other configurations of the cutoff wall end up with close probabilities of failure in all values of COV.

- Scenario 2: Both $\mathrm{K}_{\mathrm{x}}$ and $\mathrm{K}_{\mathrm{z}}$ were generated randomly, provided that $\left(\mathrm{K}_{\mathrm{x}}\right)_{\text {mean }}=\left(\mathrm{K}_{\mathrm{z}}\right)_{\text {mean }}($ Fig. 8). Similar to the first scenario, the diversion dam of configuration 1 has the lowest failure probabilities.

- Scenario 3: $\mathrm{K}_{\mathrm{x}}$ was produced stochastically whereas $\mathrm{K}_{\mathrm{z}}=0.2 \mathrm{~K}_{\mathrm{x}}$ in all random realizations. In line with Fig. 9, there are noticeable differences between probabilities of failure of all configurations, indicating the effect of anisotropic conditions. Accordingly, the cutoff wall of configuration 1 , followed by the cutoff wall of configuration 2 , gives rise to the lowest probabilities of failure, indicating that the implementation of a cutoff wall with a longer length is more effective than the construction of two walls, where each one has the half length of the single wall. Configuration 4 leads to a smaller likelihood of failure than configuration 3 , representing the influence of distance between cutoff walls. The probabilities of failure increased considerably in this scenario, signifying the influence of anisotropic hydraulic conductivity.

- Scenario 4: Considering $\left(\mathrm{K}_{\mathrm{z}}\right)_{\text {mean }}=0.2\left(\mathrm{~K}_{\mathrm{x}}\right)_{\text {mean }}$, both $\mathrm{K}_{\mathrm{x}}$ and $\mathrm{K}_{\mathrm{z}}$ were generated stochastically in the domain (Fig. 10). The results were similar to the results explained in the former scenario.

The above figures were obtained by employing the E-ACF with the autocorrelation distance of $1 \mathrm{~m}$ for all configurations. The probability of failure increases with an increase in the values of the COV in all scenarios. In addition, Figs. 11 and 12 display the CDF of the safety factor against piping for different configurations. Fig. 11 arises from isotropic random hydraulic conductivity, i.e., $K_{x}=K_{z}$, while Fig. 12 is provided with regard to $K_{z}=0.2 K_{x}$. Here, COV was 0.5. Accordingly, 
configuration 1 leads to the lowest probability of failure, confirming the good performance of the cutoff wall at the upstream face of the impervious blanket. Considering the safety factor of 1.5 for piping in anisotropic soil conditions, the probability of failure is $47 \%$ for configuration 1 , while it is between $51 \%$ and $67 \%$ for the other configurations.

\subsection{The influence of Auto-Correlation Function (ACF)}

The effect of different ACFs on the mean and standard deviation of exit hydraulic gradient for several COVs is illustrated in Fig. 13. Using E-ACF leads to a slightly greater mean and standard deviation for the exit gradient in comparison with the SOM-ACF and BN-ACF. Moreover, the mean and standard deviation of the exit hydraulic gradient for all ACFs increase with an increase in the COV. In addition, the results obtained by the application of the SOM-ACF and BN-ACF are nearly equal. Therefore, it is more conservative to use the E-ACF in the estimation of the exit hydraulic gradient for the design purposes. These results were acquired by assuming $\delta_{\mathrm{h}}=20 \mathrm{~m}$ and $\delta_{\mathrm{v}}=4 \mathrm{~m}$.

In addition, the influence of ACFs on the mean and standard deviation of the exit hydraulic gradient, as related to different horizontal and vertical autocorrelation distances, was examined.

The results confirm that the E-ACF leads to a greater mean and standard deviation of the exit hydraulic gradient. The effect of autocorrelation distance on the mean of the exit hydraulic gradient is shown in Fig. 14.

Fig. 15 shows the influence of the ACFs mentioned above on the mean and standard deviation of the seepage flow rate. These parameters are slightly lower when they are estimated using the E$\mathrm{ACF}$ for all COVs. In addition, the maximum mean of the seepage flow rate is associated with the 
SOM-ACF. The corresponding correlation surfaces of these three ACFs are depicted in Fig. 16. In this figure, the $x-y$ plane represents the seepage surface beneath the dam. The correlation surfaces of $\mathrm{E}-\mathrm{ACF}$ and $\mathrm{BN}-\mathrm{ACF}$ reveal sharp angles at the origin, while the surface resulting from the SOM-ACF indicates a rounded edge at the origin because the BN-ACF and E-ACF are not differentiable at the origin, whereas the SOM-ACF is differentiable. In the following sections, the E-ACF was selected for the generation of a random field for the sake of brevity.

\subsection{Stochastic analysis of exit hydraulic gradient}

For more probabilistic investigation of seepage flow beneath the diversion dam, configuration 1 (see Fig. 2) was considered for further investigation. Fig. 17 illustrates the histogram of the exit hydraulic gradient for the case of isotropic hydraulic conductivity, assuming COV=0.5 and $\delta_{\mathrm{h}}=\delta_{\mathrm{v}}=1 \mathrm{~m}$. The lognormal probability distribution agrees more with the histogram than normal distribution. The correlation coefficient $\left(R^{2}\right)$ of 0.977 confirms this close agreement of lognormal distribution. In this case, the mean and standard deviation of the exit hydraulic gradient are computed as 0.4604 and 0.112 , respectively, while the deterministic value is 0.4612 . Therefore, the likelihood that the exit hydraulic gradient will be greater than the deterministic value can be estimated using the following relationship.

$$
\mathrm{P}\left(\mathrm{i}_{\text {exit }}>\mathrm{i}_{\text {det }}\right)=1-\Phi\left(\frac{\left.\ln \left(\mathrm{i}_{\text {det }}\right)-\mu_{\ln \left(\mathrm{i}_{\text {exit }}\right)}\right)}{\sigma_{\ln \left(\mathrm{i}_{\text {exit }}\right)}}\right)=1-\Phi(0.1273)=1-0.55=0.45
$$

where $\mu_{\ln \left(i_{\text {exit }}\right)}$ and $\sigma_{\ln \left(i_{\text {exi }}\right)}$ are the mean and standard deviation of $\ln \left(\mathrm{i}_{\text {exit }}\right)$, which are calculated to be -0.8044 and 0.2396 , respectively (see Eqs. 2 and 3). Accordingly, there is a $45 \%$ probability that the design based on the deterministic value is non-conservative. 
The variations in the mean and standard deviation of the exit hydraulic gradient are illustrated in Figs. 18 and 19, respectively. Several COVs, ranging from 0.125 to 1, in addition to different isotropic and anisotropic autocorrelation distances, were taken into consideration. Two types of behavior are observed in Fig. 18 regarding the increase or decrease in the mean value of $i_{\text {exit. }}$ The mean of the exit hydraulic gradient increases with an increase in COV for the autocorrelation distances of 2, 4, 8, and $20 \mathrm{~m}$. However, for $\delta_{\mathrm{h}}=\delta_{\mathrm{v}}=1 \mathrm{~m}$, there is a tendency towards the mean of the exit gradient following the deterministic value at the lower COV and falling behind this value for the greater COV. Similar results were also reported by Griffiths and Fenton [21], possibly due to more variability in the soil properties when the autocorrelation distance is small. Furthermore, the standard deviation of the exit hydraulic gradient increases with an increase in the values of COV with respect to different autocorrelation distances (Fig. 19).

\subsection{Stochastic analysis of seepage flow rate}

Fig. 20 shows the relationship between the estimated means of the seepage flow rate and the $\mathrm{COV}$, considering several autocorrelation distances. As shown, the mean of the seepage flow rate increases with an increase in the autocorrelation distance. However, there is a decrease in the seepage flow rate with an increase in the values of COV. In addition, an increase in both the autocorrelation distance and coefficient of variation leads to higher standard deviations (Fig. 21).

\subsection{Stochastic analysis of the uplift force}


The random generation of hydraulic conductivity produces a distribution for the uplift force underneath the dam. Fig. 22 displays the histogram of the uplift force in addition to the induced normal and lognormal distribution regarding isotropic hydraulic conductivity, while Fig. 23 has been drawn for anisotropic soil conditions. As shown, both normal and lognormal distributions fit the histograms well. The high values of correlation coefficients that are greater than 0.99 confirmed these close agreements. In these calculations, $\mathrm{COV}=0.5$, and $\delta_{\mathrm{h}}=\delta_{\mathrm{v}}=1 \mathrm{~m}$. Moreover, the means of the uplift force attained by assuming both isotropic and anisotropic hydraulic conductivity are $423.1 \mathrm{kN}$ and $392.6 \mathrm{kN}$, respectively, indicating higher uplift force in the isotropic conditions.

\subsection{Stochastic analysis of sliding stability}

The PDF of the safety factor against sliding was estimated for both ordinary and earthquake load combinations, shown in Fig. 24. The probability distribution of uplift force was included in the computations. Two scenarios were considered for the shear strength parameters. First, these parameters were modeled as random variables. In the second case, the concept of random field was used to describe $\mathrm{c}_{\mathrm{i}}$ and $\phi_{\mathrm{i}}$. In both load combinations mentioned, the standard deviation of the safety factor increases with an increase in the autocorrelation distance, while the estimated mean remains nearly unchanged (Fig. 24).

The mean and standard deviation of the safety factor associated with the ordinary and earthquake load cases, in addition to the corresponding reliability indices and probabilities of failure, are reported in Tables 6 and 7, respectively. Considering the ordinary load combination, the estimated mean of the safety factor against sliding is nearly 3.18 when the autocorrelation distance ranges from 1 to 10 , while the standard deviation increases from 0.26 to 0.44 . The probability of failure in this combination is very small since the limit state surface is considered to 
be 1 , whereas the diversion dam is designed based on the deterministic safety factor of 3 . The reliability indices greater than 5 confirm the safety of the dam at this load case (Table 6). Regarding the earthquake load combination, the estimated mean of the safety factor is approximately 1.56 for all autocorrelation distances, and the related standard deviation varies from 0.336 to 0.380 (Table 7). The probability of failure is estimated between 4.8 and $7.1 \%$, insofar as the highest probability of failure is obtained for the autocorrelation distance of $10 \mathrm{~m}$. In addition, the reliability indices are in the range of 1.466 to 1.656 , indicating a considerable decrease in comparison with the reliability indices of the ordinary load combination. Regarding the autocorrelation distance of 5 $\mathrm{m}$, the PDF of the safety factor resulting from random field discretization agrees well with the PDF obtained from random variable assumption (see Fig. 24).

The above computations are based on the truncated normal distribution of input parameters. Both truncated normal and lognormal distributions have been used in the literature $[43,48-50]$ to explain non-negative soil mechanical properties. The effects of normal and lognormal distributions of shear strength parameters on the distributions of the safety factor are displayed in Fig. 25, considering both ordinary and earthquake load combinations. As shown, the distributions of shear strength parameters mentioned above end up in close agreement. Of note, these agreements are based on the assumed mean and standard deviations of the input parameters.

Pursuing this topic a step further, the histogram of the safety factor using an autocorrelation distance of $5 \mathrm{~m}$ was selected. In terms of the ordinary load pattern, both normal and lognormal distributions fit the histogram of the safety factor satisfactorily (Fig. 26a). The $\mathrm{R}^{2}$ values greater than 0.99 confirm these high levels of agreement. However, according to Fig. 26b, the probability distribution of the safety factor with respect to the earthquake load combination is closer to the skew normal distribution. The correlation coefficient of the skew normal distribution is estimated 
to be 0.963 , while this coefficient is less than 0.92 for the normal and lognormal distributions. The skew normal distribution is defined by Eq. 19 [51-52].

$$
f(x)=\frac{1}{\omega \sqrt{2 \pi}} \exp \left(-\frac{(x-\xi)^{2}}{2 \omega^{2}}\right)\left(1+\operatorname{erf}\left(\frac{\alpha}{\sqrt{2}} \frac{(x-\xi)}{\omega}\right)\right)
$$

In this equation, $\alpha$ is an indicator of skewness, and $\xi$ and $\omega$ are the model constants. The mean and standard deviation of this distribution in addition to the value of skewness are calculated using Eqs. 20 to 22 .

$$
\begin{gathered}
\mu_{\mathrm{sk}}=\xi+\omega \lambda \sqrt{\frac{2}{\pi}} \\
\sigma_{\mathrm{sk}}=\omega \sqrt{1-\frac{2 \lambda^{2}}{\pi}} \\
\mathrm{S}=\frac{4-\pi}{2} \frac{\left(\lambda \sqrt{\frac{2}{\pi}}\right)^{3}}{\left(1-\frac{2 \lambda^{2}}{\pi}\right)^{\frac{3}{2}}}
\end{gathered}
$$

In the above equations, $\lambda$ is defined by:

$$
\lambda=\frac{\alpha}{\sqrt{1+\alpha^{2}}}
$$

The estimated parameters of the distributions for the earthquake load combination mentioned above are listed in Table 8. The reason for the skewness of the PDF under the earthquake load pattern is that the seismic coefficients are described by the exponential distribution, resulting in the skewness of the PDF. 
Regarding isotropic and anisotropic hydraulic conductivity, the CDFs of the safety factor under the ordinary and earthquake load combinations are plotted in Fig. 27. As shown, the CDF curves obtained from the anisotropic hydraulic conductivity are plotted at the right side of the curve attained from isotropic conductivity, implying that the probability of failure is reduced by assuming anisotropic random hydraulic conductivity. Considering the ordinary load combination for which the minimum deterministic safety factor is three, the probability of failure associated with isotropic and anisotropic situations is $34 \%$ and $27 \%$, respectively (Fig. 27a). Moreover, the

possibility of failure at the earthquake load combination with the safety factor of one is equal to $6 \%$ and 5.5\% under isotropic and anisotropic cases, respectively (Fig. 27b). Consequently, estimation of the safety factor against sliding under isotropic soil conditions for more conservative design is recommended.

Different values of the safety factor are mentioned in the reference books $[1,3,12]$. The USBR has proposed minimum safety factors of 4 and 1.5 for the ordinary and earthquake load combinations, respectively [1]. Accordingly, for isotropic circumstances, the relevant probability of failure is $97 \%$ in terms of the ordinary load combination and is $44 \%$ for the earthquake load pattern. This discussion indicates that the probability of failure increases noticeably with the greater values of the safety factors, implying the necessity of the probabilistic considerations in the design of diversion dams.

\subsection{Sensitivity analysis}

Sensitivity analysis was also performed to examine the prominence of each stochastic input parameter on the sliding stability. The mean of each individual stochastic parameter was increased by $20 \%$, while the means of the other stochastic parameters were kept constant. The CDF curves 
arisen from both ordinary and earthquake load patterns are illustrated in Figs. 28 and 29, respectively. In these figures, there are multiple curves on both sides of the primary CDF curve, indicating the positive and negative influence of different parameters. The CDF of the safety factor moves rightward with an increase in the shear resistance parameters of the sliding surface (c and $\phi)$ and the sediment friction angle $\left(\phi_{\mathrm{s}}\right)$. However, the influence of $\mathrm{c}$ and $\phi$ on the CDF of the safety factor is much greater than the influence of $\phi_{s}$. In addition, the CDF curves shift leftward with a rise in the sediment unit weight as well as the horizontal and vertical coefficients of the earthquake. The horizontal coefficient of the earthquake has the most leftward variation in the CDF of the safety factor. Similar sensitivity outcomes were attained when a $10 \%$ increment was assumed for the mean values of the parameters.

\section{Conclusions}

In this article, the influence of uncertainty in the soil properties, earthquake coefficients, and sediment characteristics was investigated in the stability of a diversion dam against piping and sliding. In addition, the efficiency of four cutoff wall configurations, comprising a single wall and two walls with half the length of the single wall, was explored stochastically using a twodimensional random finite element method. The conditions of isotropic hydraulic conductivity lead to similar probabilities of failure for all cutoff wall configurations, while the assumption of anisotropic conditions provides different probabilities of failure for each configuration. Moreover, higher probabilities of failure stem from anisotropic hydraulic conductivity of the soil in comparison with the probabilities of failure obtained from isotropic circumstances. Among the introduced cutoff wall configurations, the use of a single cutoff wall upstream facing the impervious blanket (configuration 1) gives rise to the least likelihood of failure for all COV. In 
addition, the mean of the exit hydraulic gradient is higher than the deterministic value for the autocorrelation distances greater than one, while it falls behind the deterministic value for the autocorrelation distance equal to one. In terms of the effect of different ACFs (E-ACF, SOM-ACF, and $\mathrm{BN}-\mathrm{ACF}$ ), the employment of E-ACF provides a slightly greater mean and standard deviation of the exit hydraulic gradient. However, the seepage flow rate is slightly greater when estimated using the SOM-ACF.

Regarding the probabilistic analysis of sliding stability, the ordinary and earthquake load combinations were considered. The shear strength parameters of the sliding plane were described stochastically using random field discretization. The probability of failure increases when the autocorrelation distance varies from 1 to $10 \mathrm{~m}$. The PDF of the safety factor follows both normal and lognormal distributions in the case of ordinary load combinations. Nonetheless, the skew normal distribution gives the best agreement with the PDF of the safety factor in the case of the earthquake load combination.

The sensitivity results show that the probability of failure decreases considerably with an increase in the shear resistance parameters of the sliding surface of the dam and the soil. However, the probability of failure increases noticeably with an increase in the horizontal coefficient of the earthquake. 


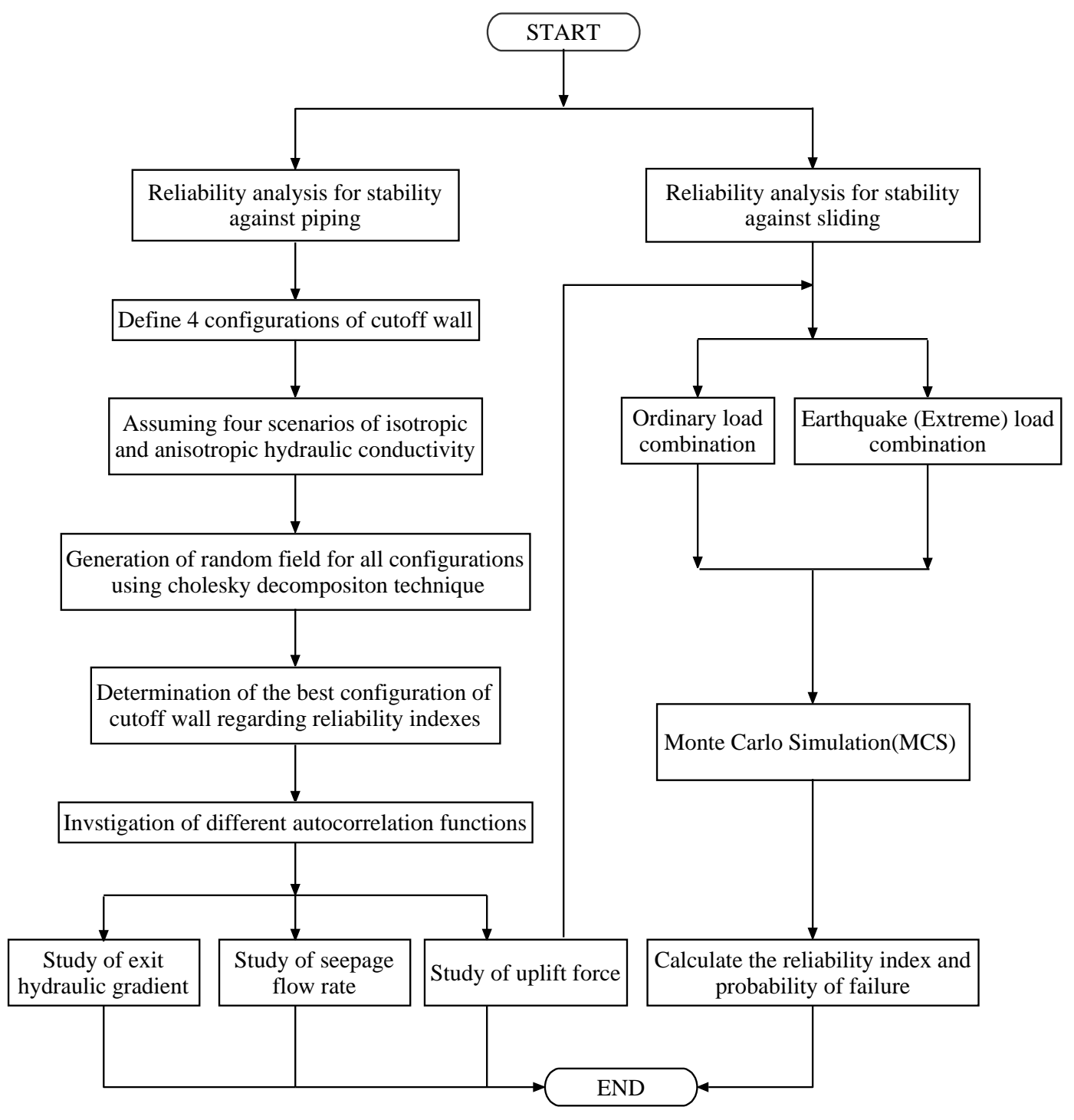

Fig. 1. The flow chart of the procedure. 


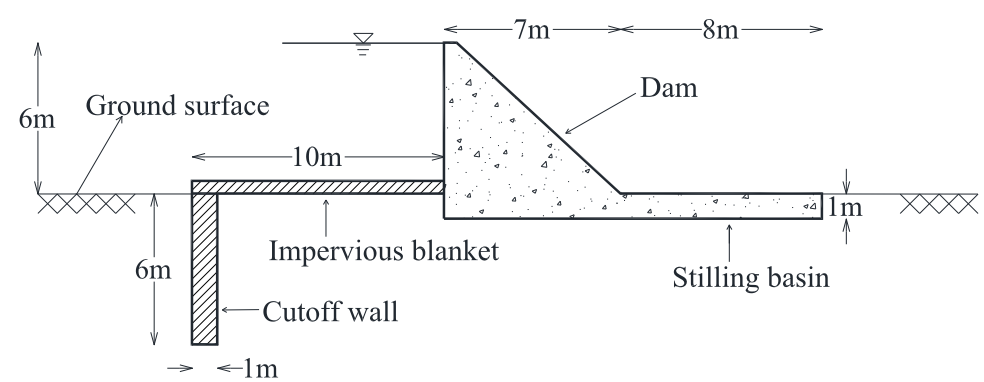

(a)

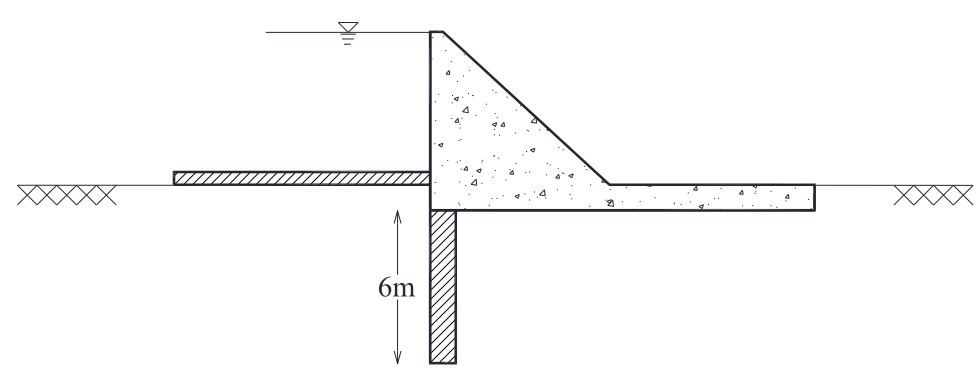

(b)

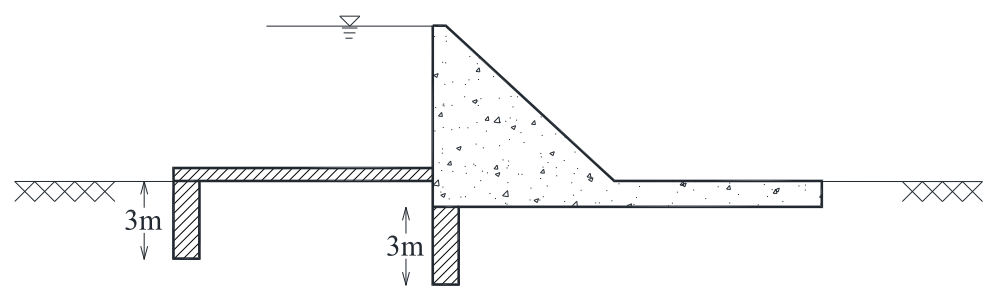

(c)

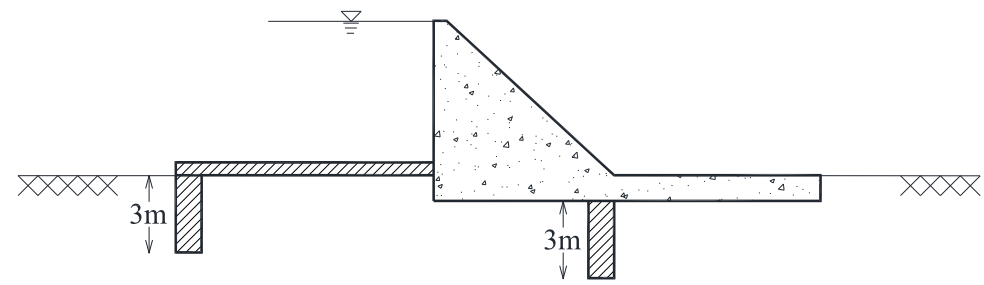

(d)

Fig. 2. Geometry of the studied diversion dam. (a) configuration 1. (b) configuration 2. (c) configuration 3. (d) configuration 4. 


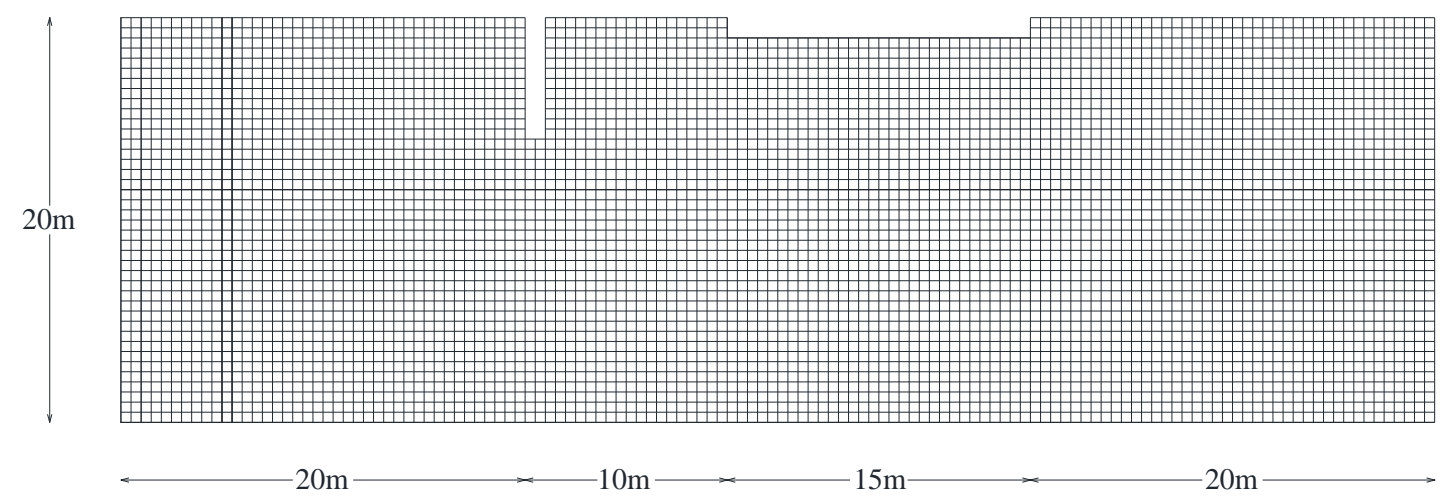

Fig. 3. Finite element discretization of the soil beneath the diversion dam. All elements are $0.5 \mathrm{~m} \times 0.5$ m squares.
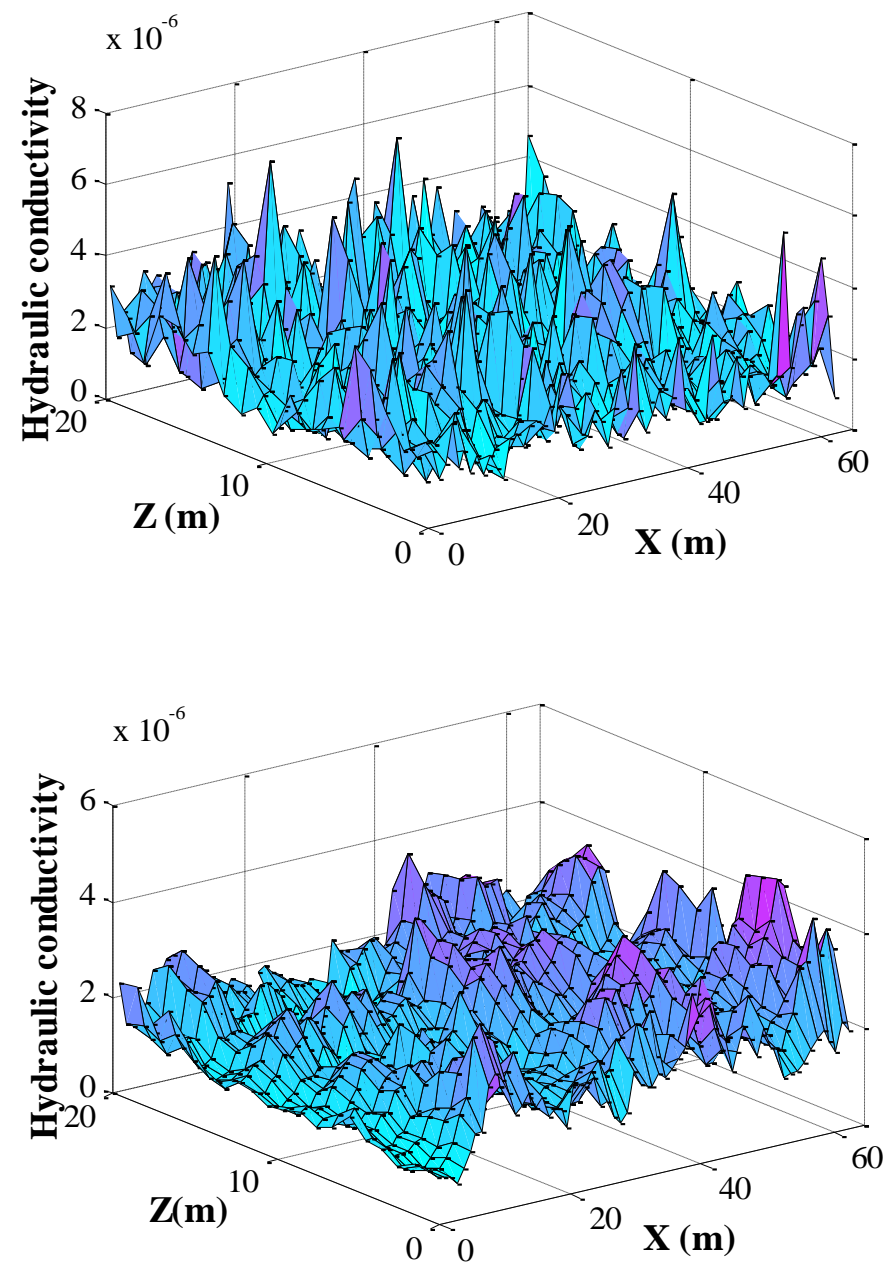

Fig. 5. Spatial variability of hydraulic conductivity using E-ACF for COV=0.5 and $\delta_{\mathrm{h}}=\delta_{\mathrm{v}}=10 \mathrm{~m}$. 


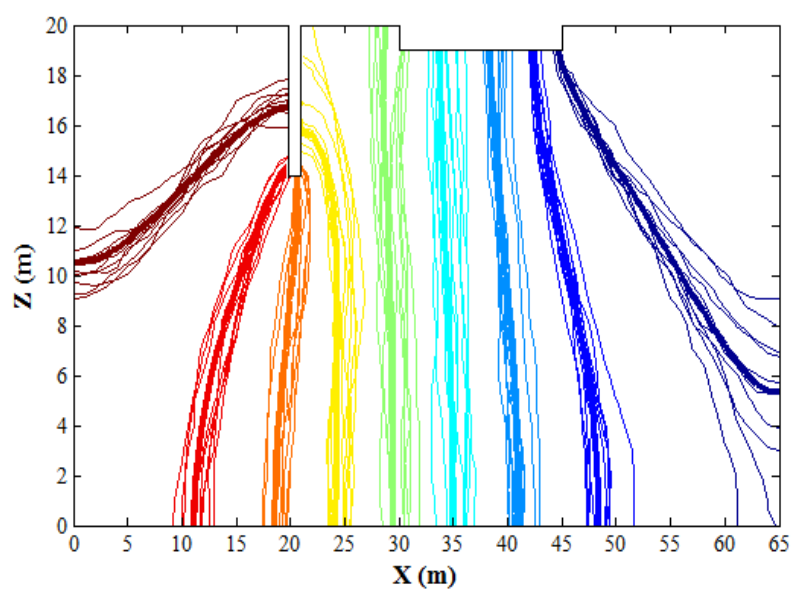

(a)

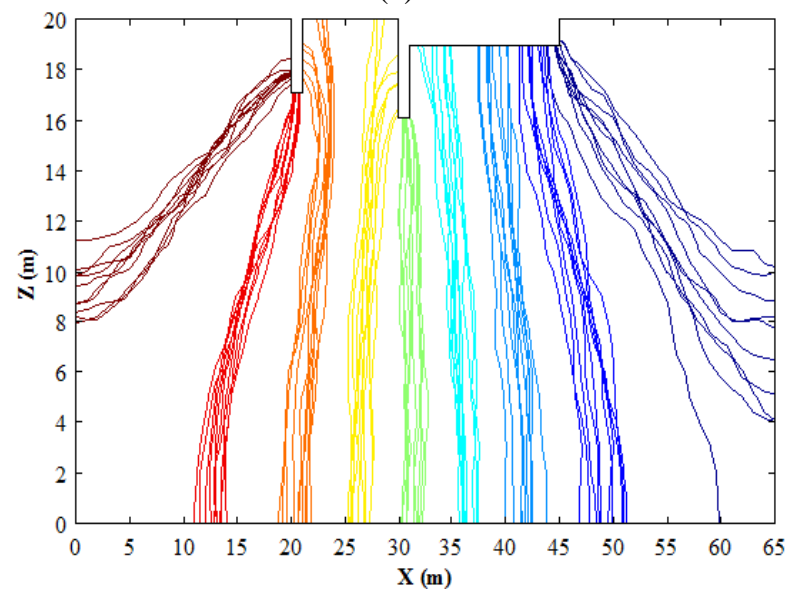

(c)

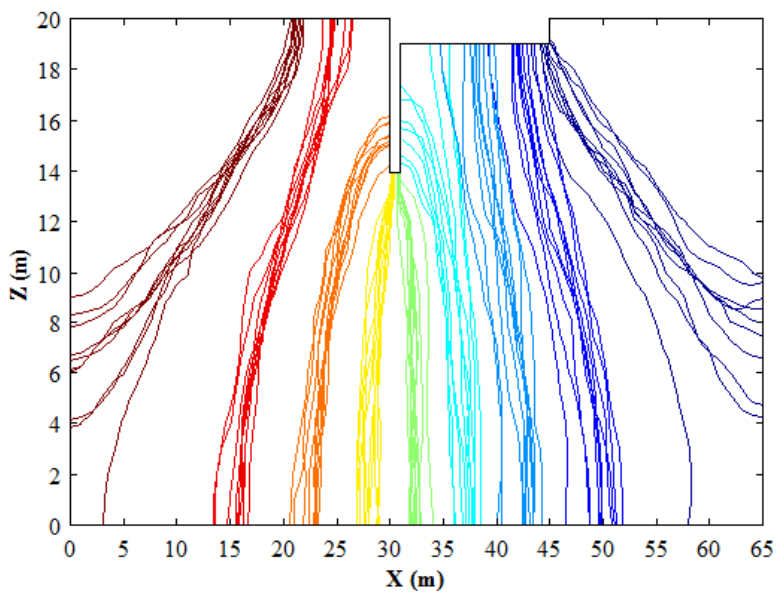

(b)

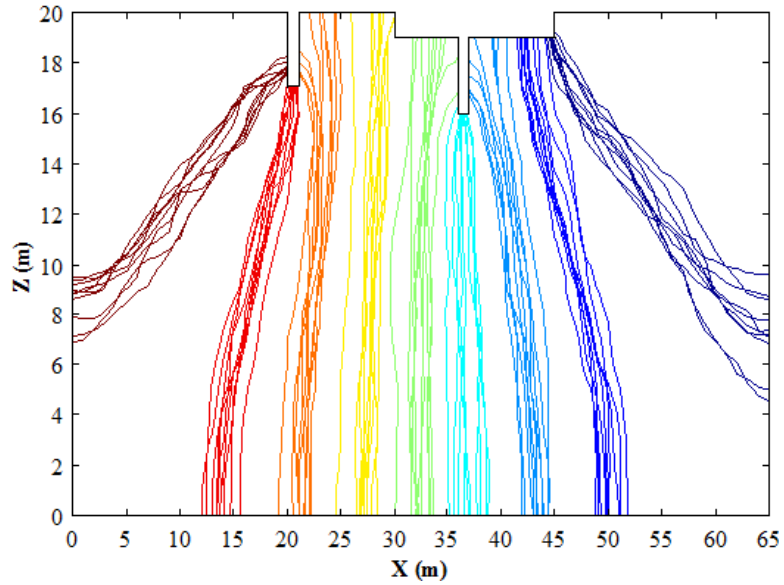

(d)

Fig. 6. Stochastic equipotential lines. (a) configuration 1. (b) configuration 2. (c) configuration 3. (d) configuration 4 . 


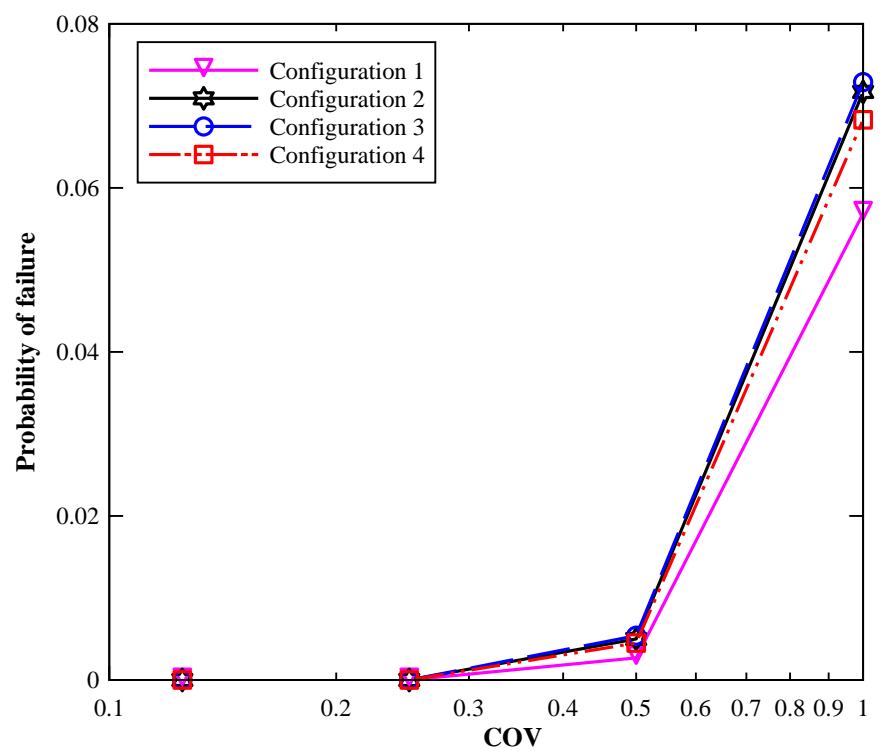

Fig. 7. Influence of COV on the probability of failure of all configurations (scenario 1).

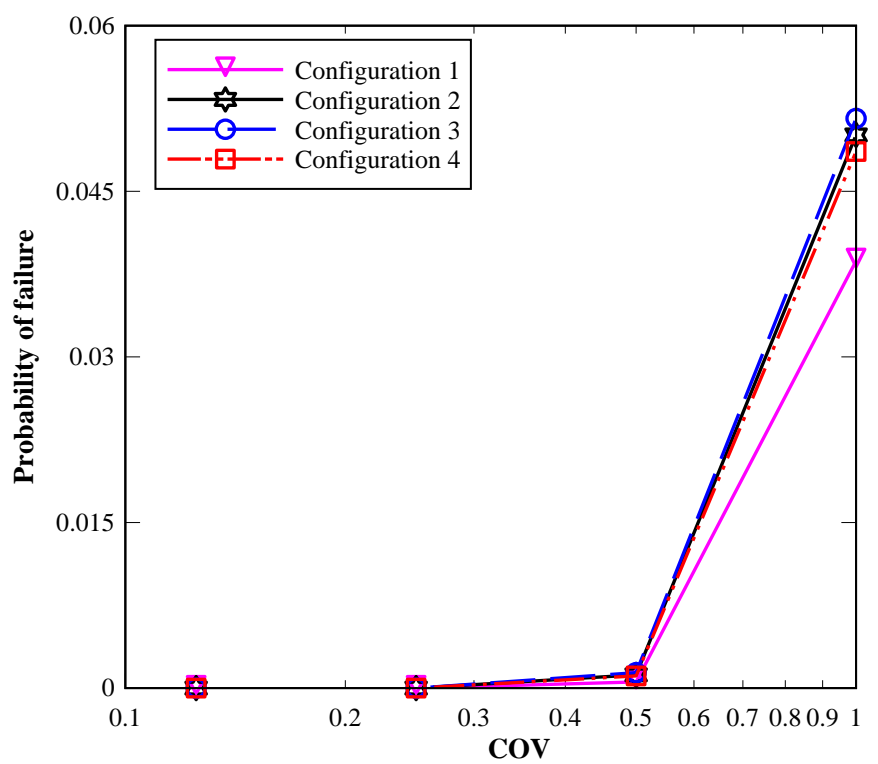

Fig. 8. Influence of COV on the probability of failure of all configurations (scenario 2). 


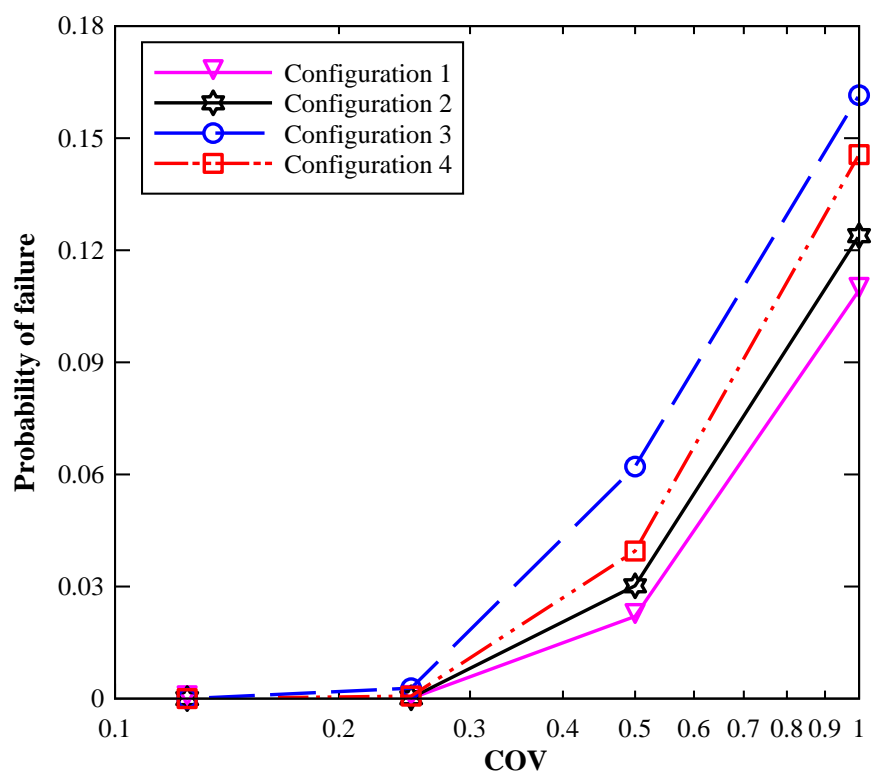

Fig. 9. Influence of COV on the probability of failure of all configurations (scenario 3).

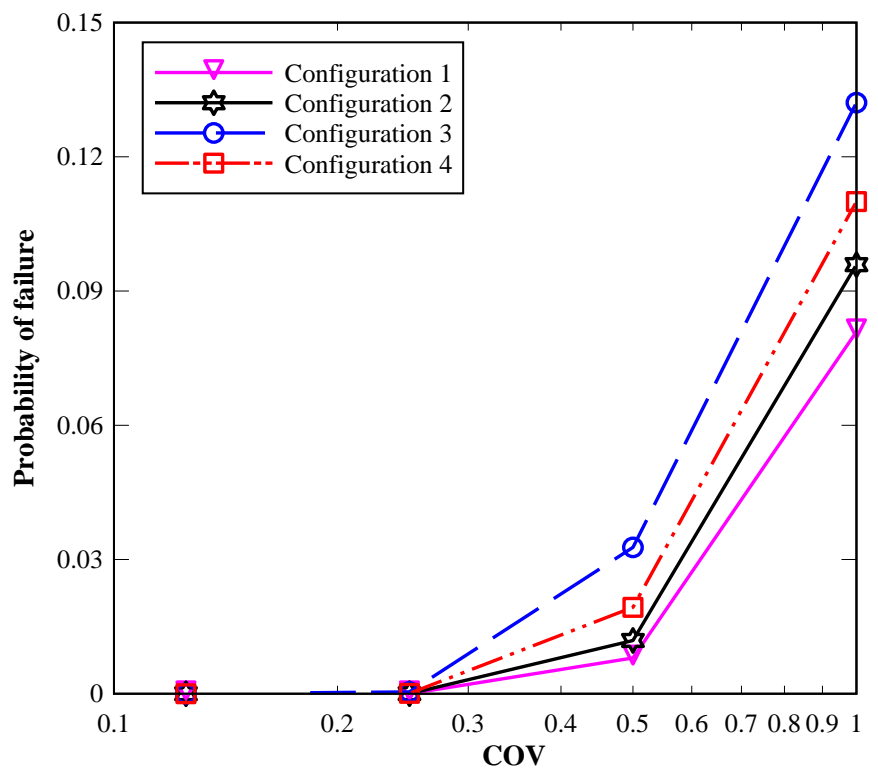

Fig. 10. Influence of COV on the probability of failure of all configurations (scenario 4). 


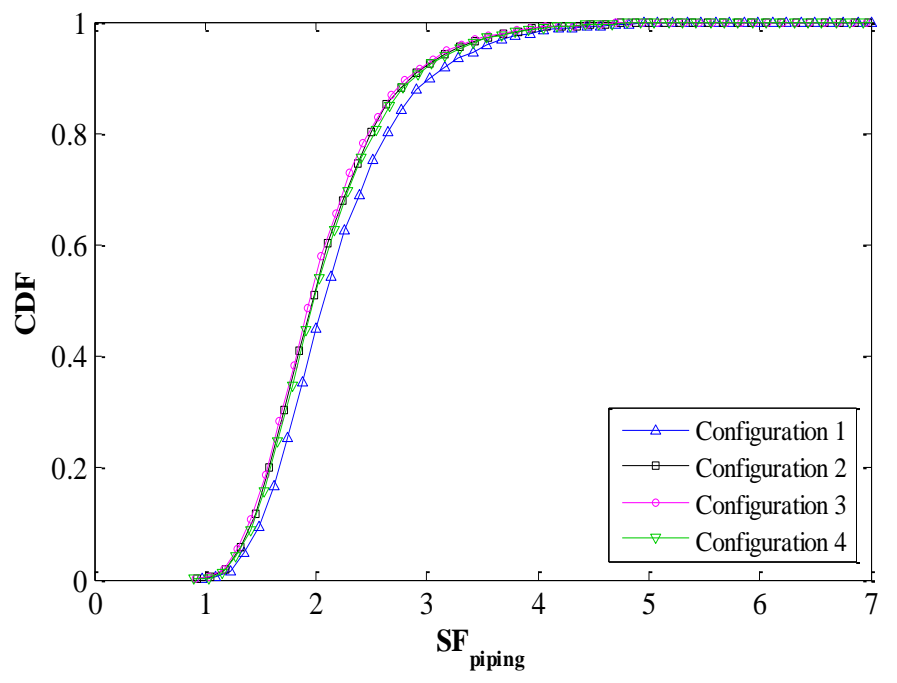

Fig. 11. CDFs related to the safety factor against piping associated with isotropic conditions (scenario 1).

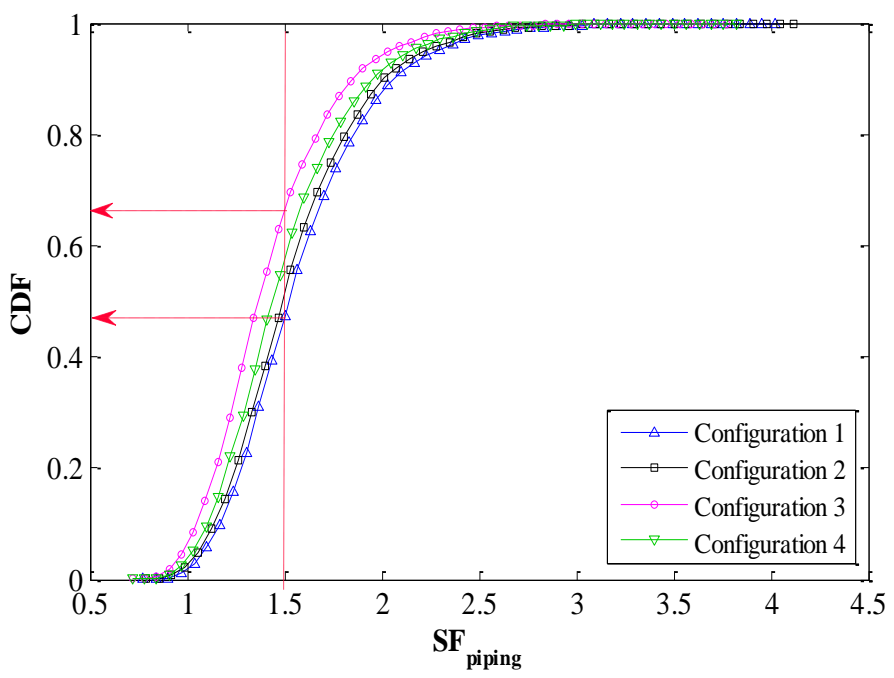

Fig. 12. CDFs related to the safety factor against piping associated with anisotropic conditions (scenario 3). 


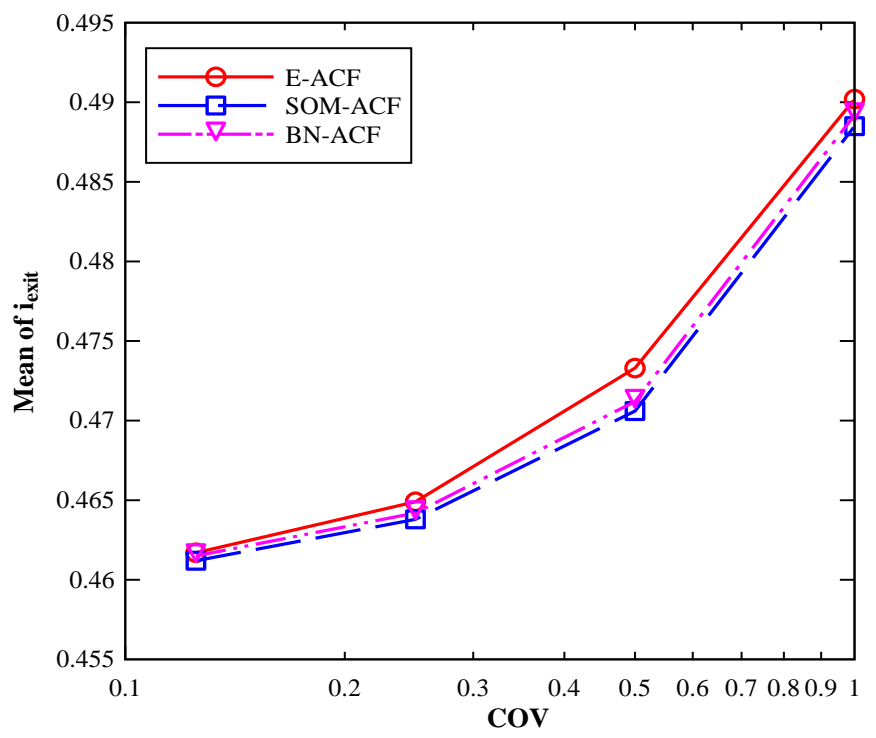

(a)

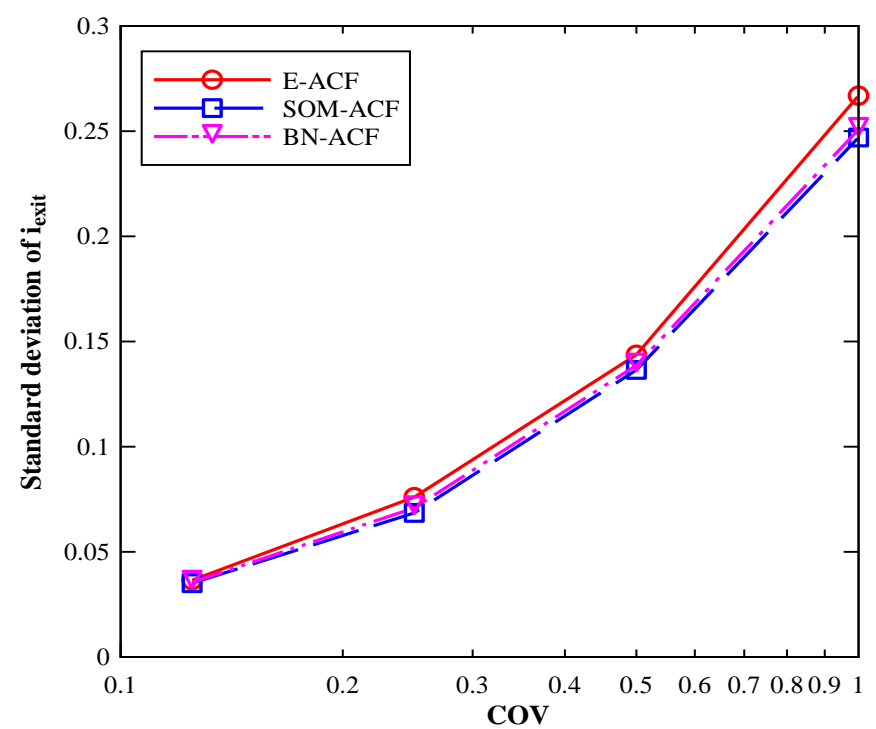

(b)

Fig. 13. Influence of different AFCs on the exit hydraulic gradient ( $\left.i_{\text {exit }}\right)$. (a) mean of $i_{\text {exit. }}$ (b) standard deviation of $i_{\text {exit. }}$ 


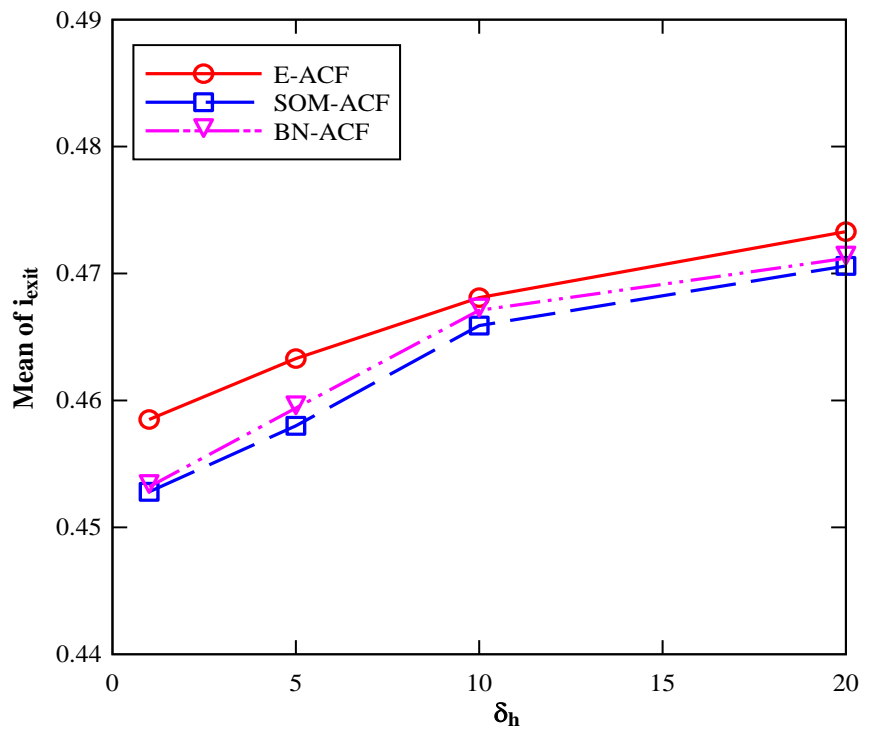

(a)

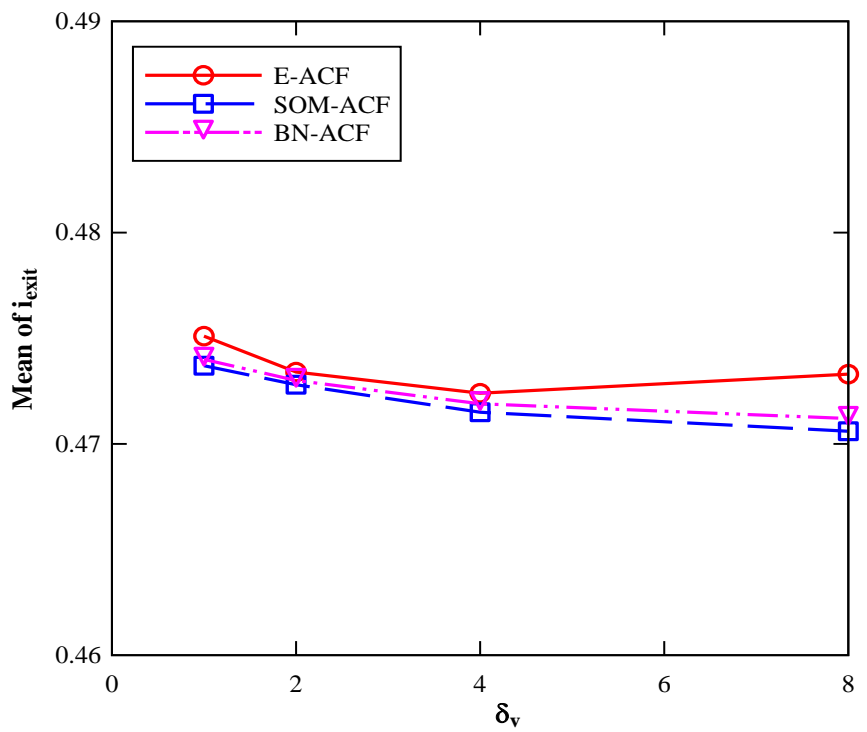

(b)

Fig. 14. Influence of horizontal and vertical autocorrelation distance on the mean of $i_{\text {exit. }}$ (a) mean of $i_{\text {exit }}$ vs. horizontal autocorrelation distance. (b) mean of $i_{\text {exit }} v$ v. vertical autocorrelation distance. 


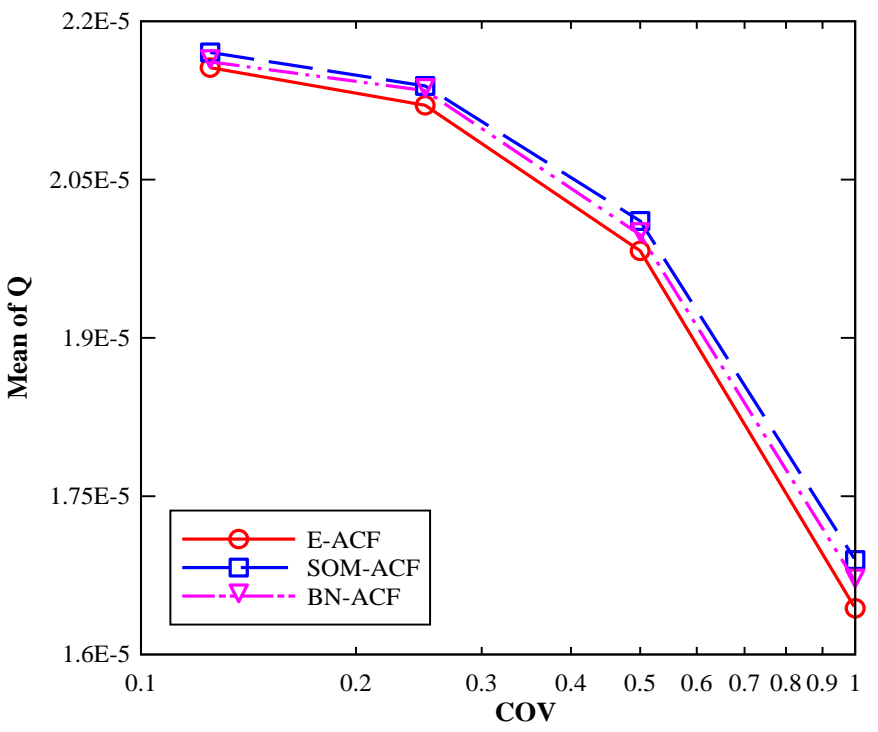

(a)

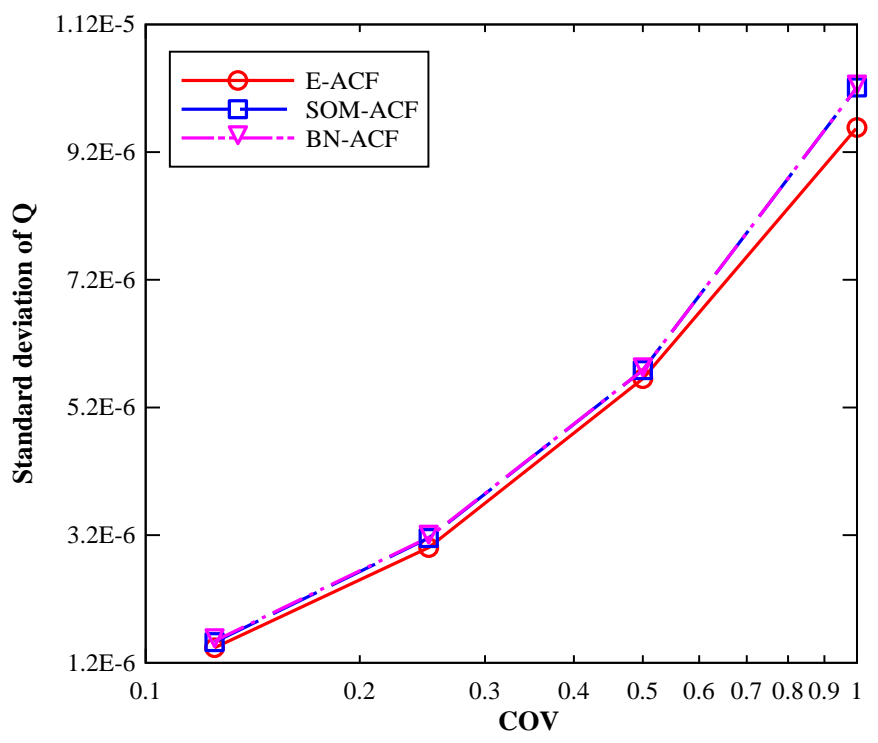

(b)

Fig. 15. Influence of different ACFs on the seepage flow rate (Q). (a) mean of Q. (b) standard deviation of Q. 


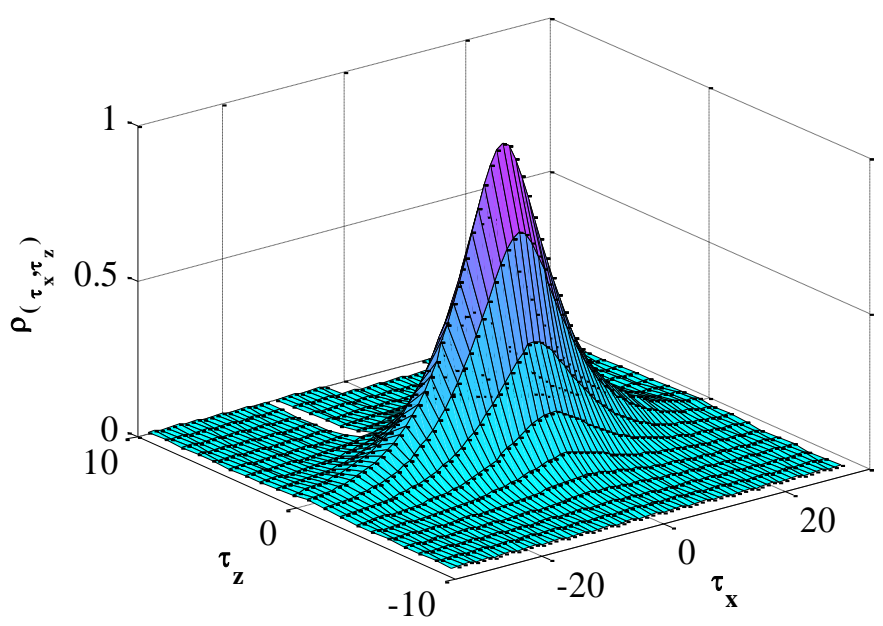

(a)

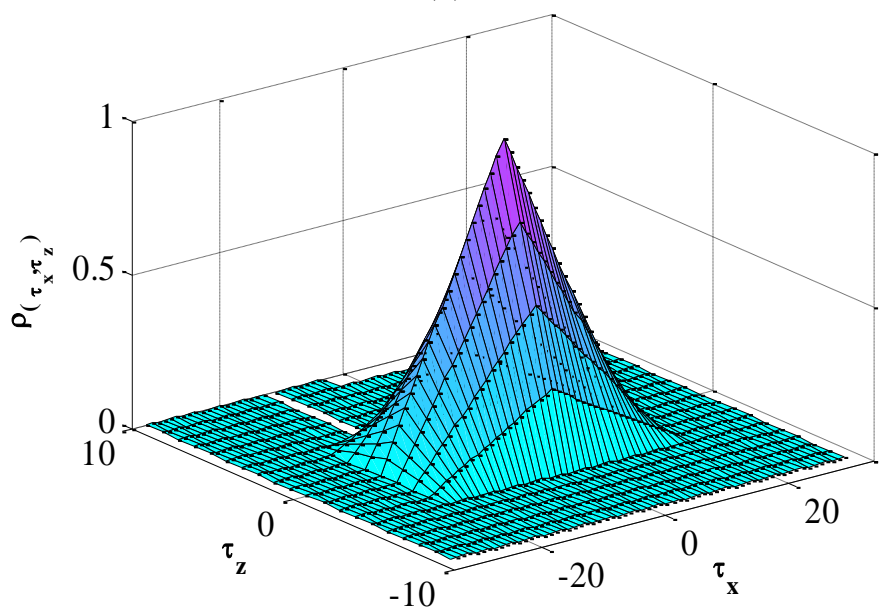

(b)

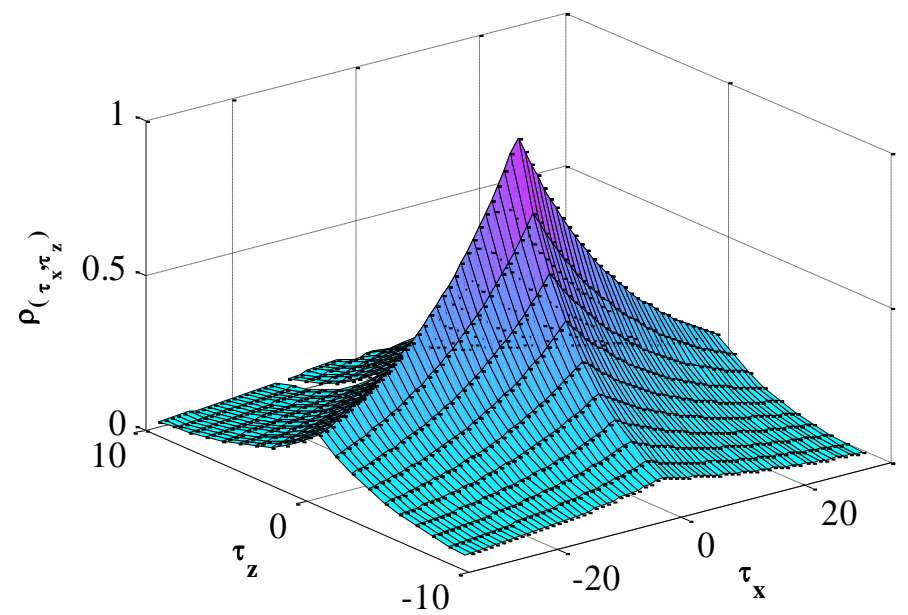

(c)

Fig. 16. Surfaces of ACFs. (a) SOM-ACF (b) BN-ACF (c) E-ACF 


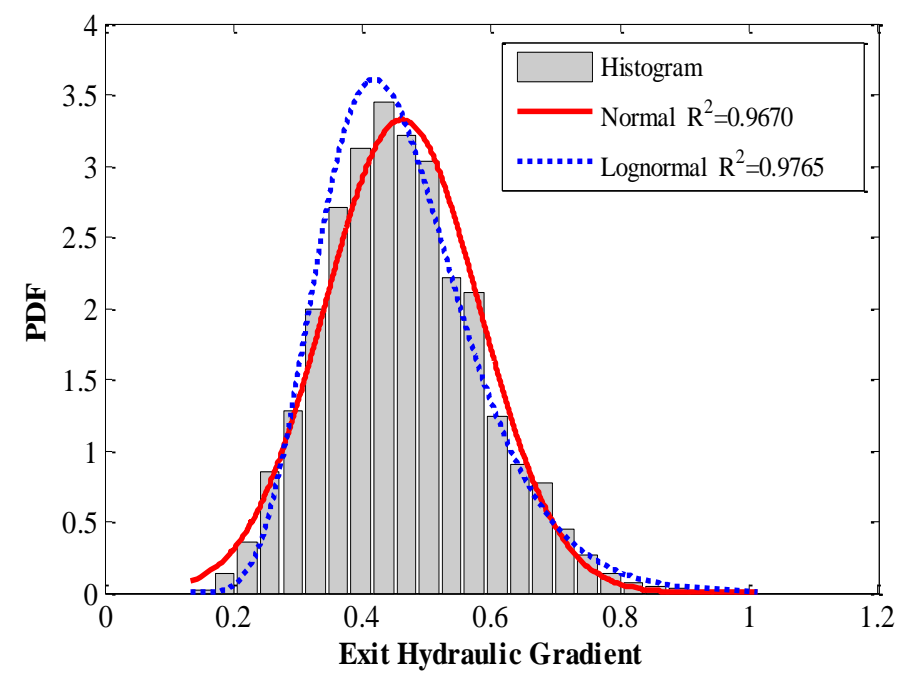

Fig. 17. Histogram of exit hydraulic gradient together with normal and lognormal fits corresponding to $\mathrm{COV}=0.5$ and $\delta_{h}=\delta_{v}=1 \mathrm{~m}$.

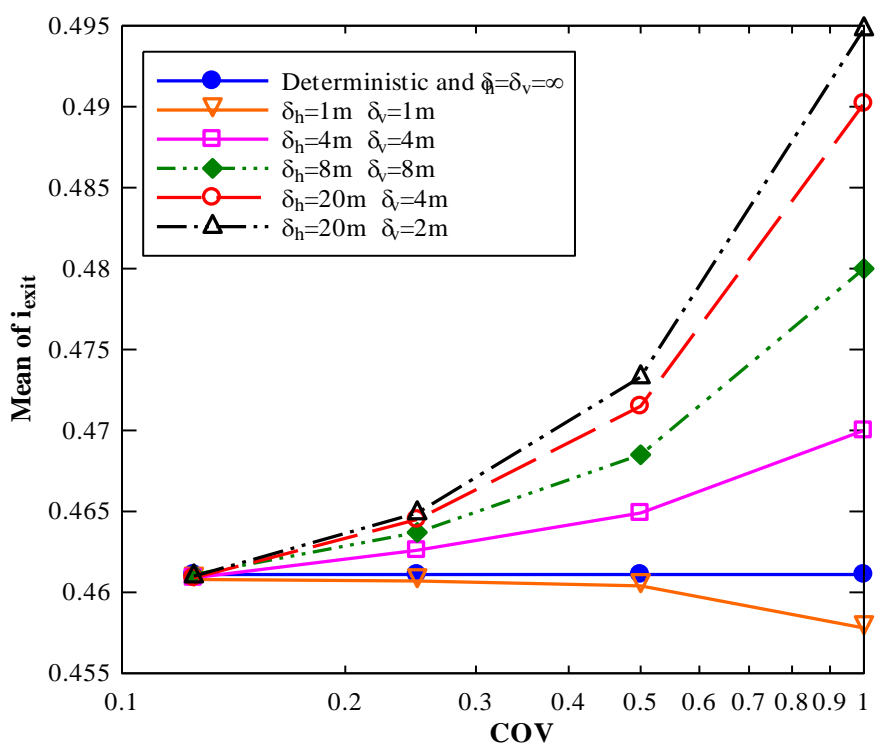

Fig. 18. Influence of COV and autocorrelation distance on the mean of the exit hydraulic gradient. 


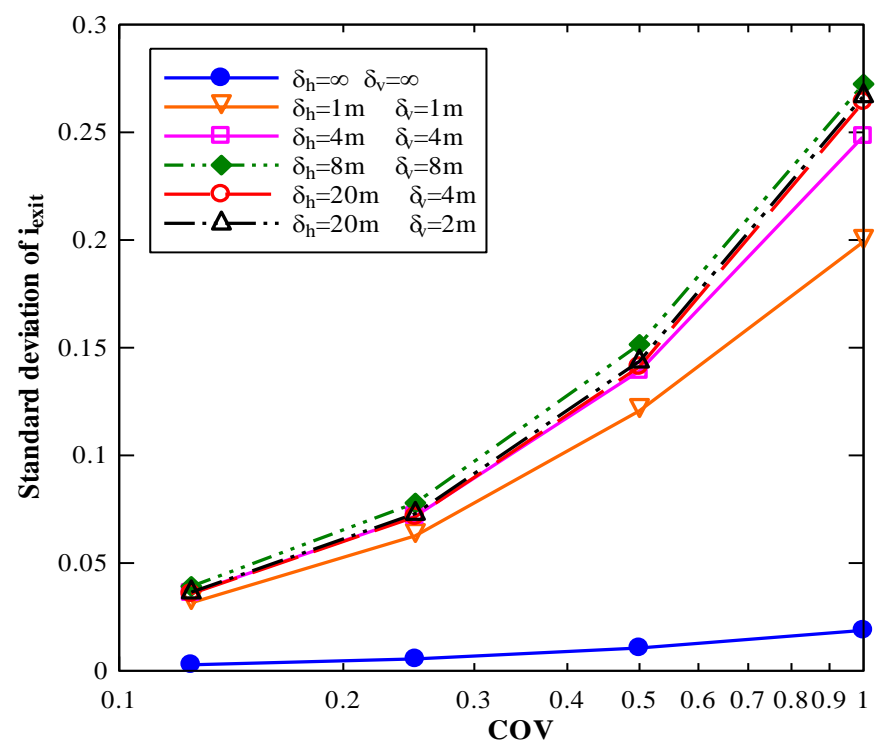

Fig. 19. Influence of COV and autocorrelation distance on the standard deviation of the exit hydraulic gradient.

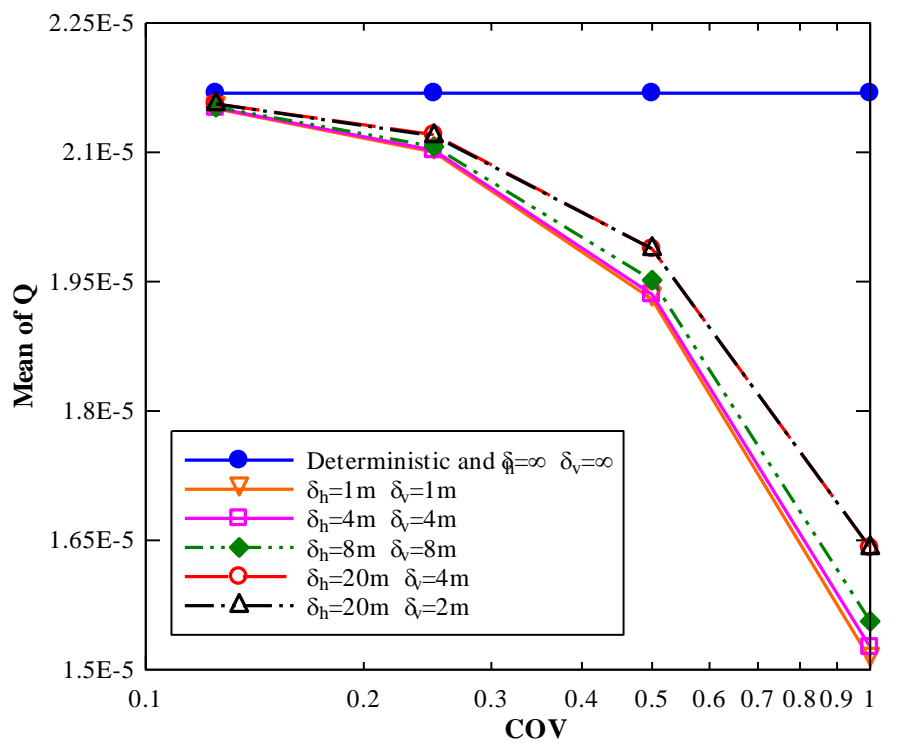

Fig. 20. Influence of COV and autocorrelation distance on the mean seepage flow rate. 


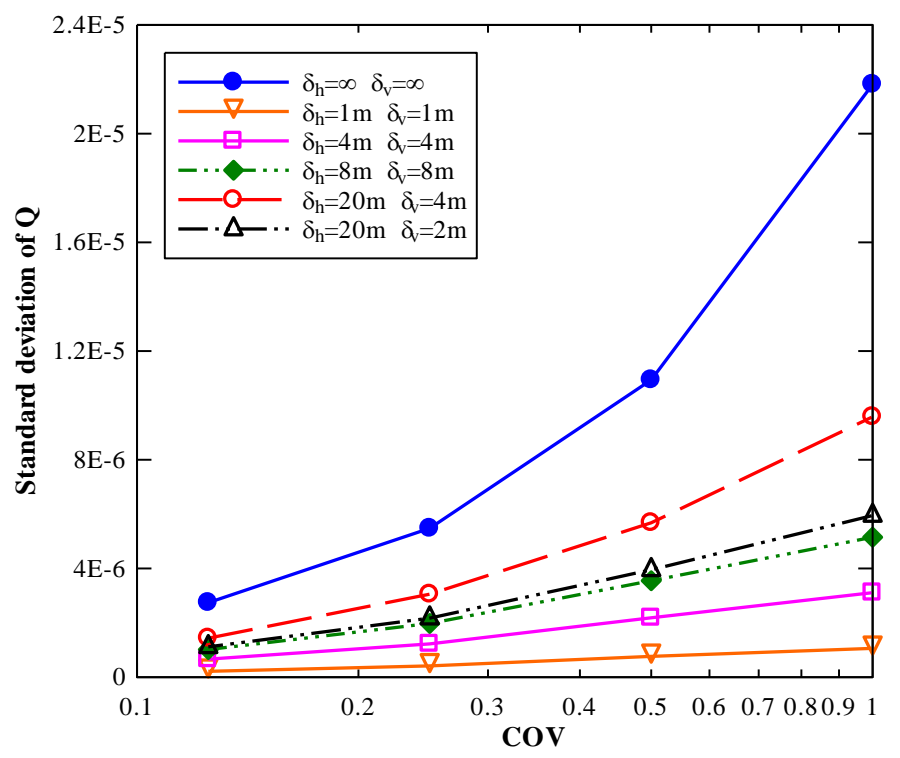

Fig. 21. Influence of COV and autocorrelation distance on the standard deviation of the seepage flow rate.

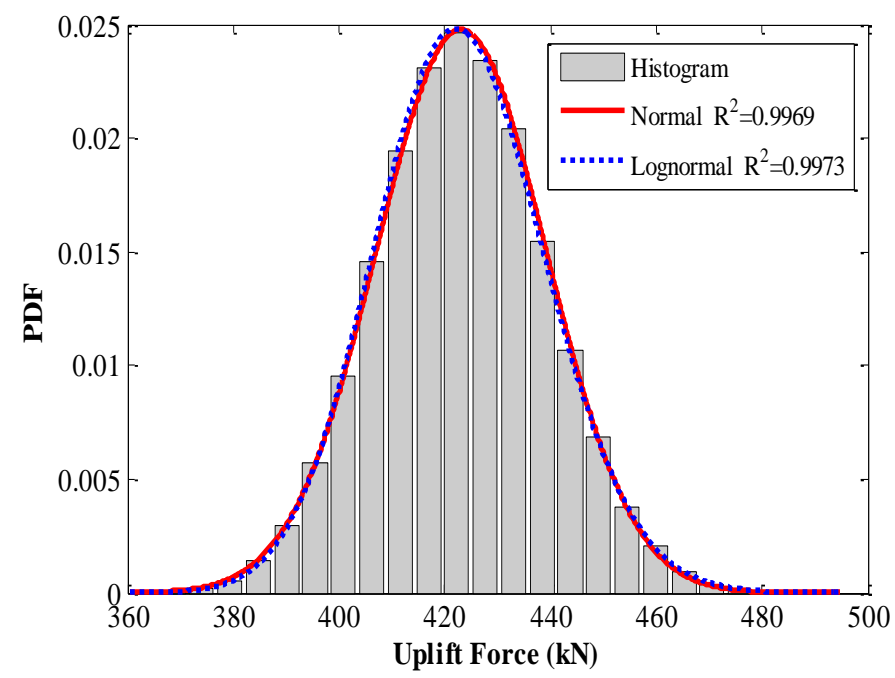

Fig. 22. Histogram of uplift force together with normal and lognormal fits for isotropic soil conditions. 


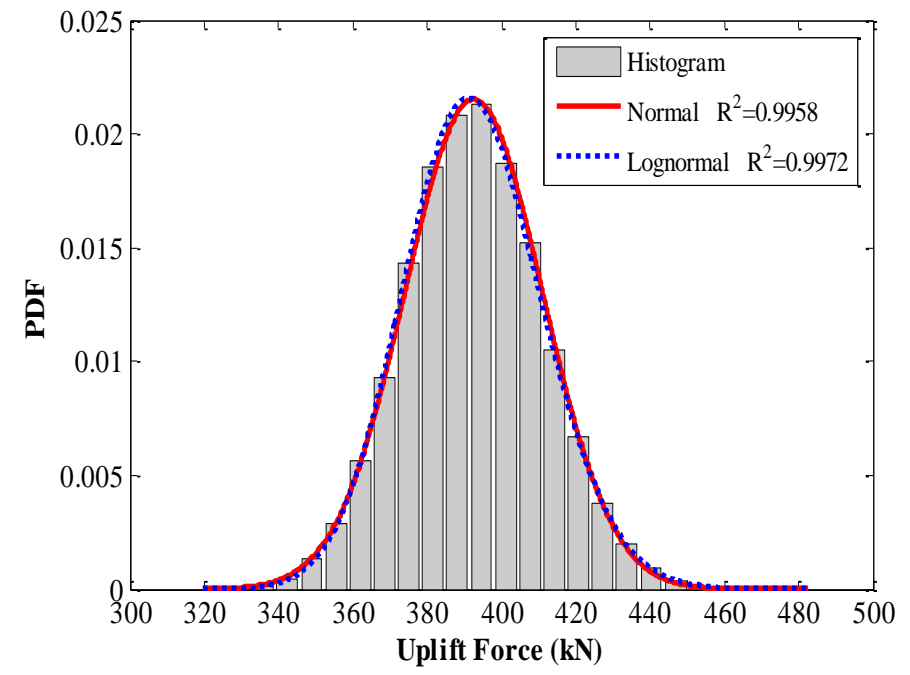

Fig. 23. Histogram of uplift force together with normal and lognormal fits for anisotropic soil conditions. 


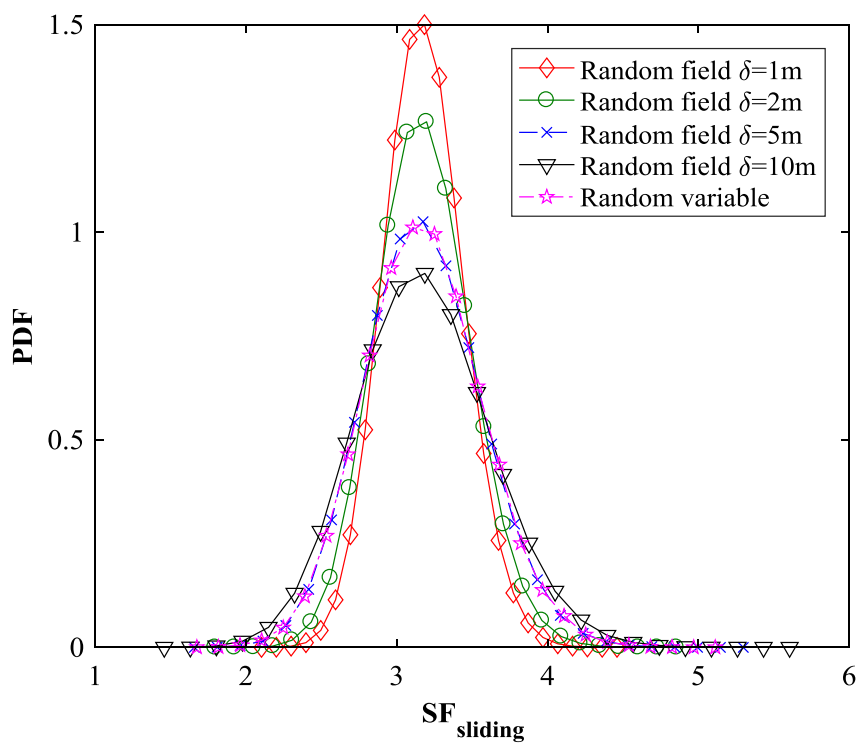

(a)

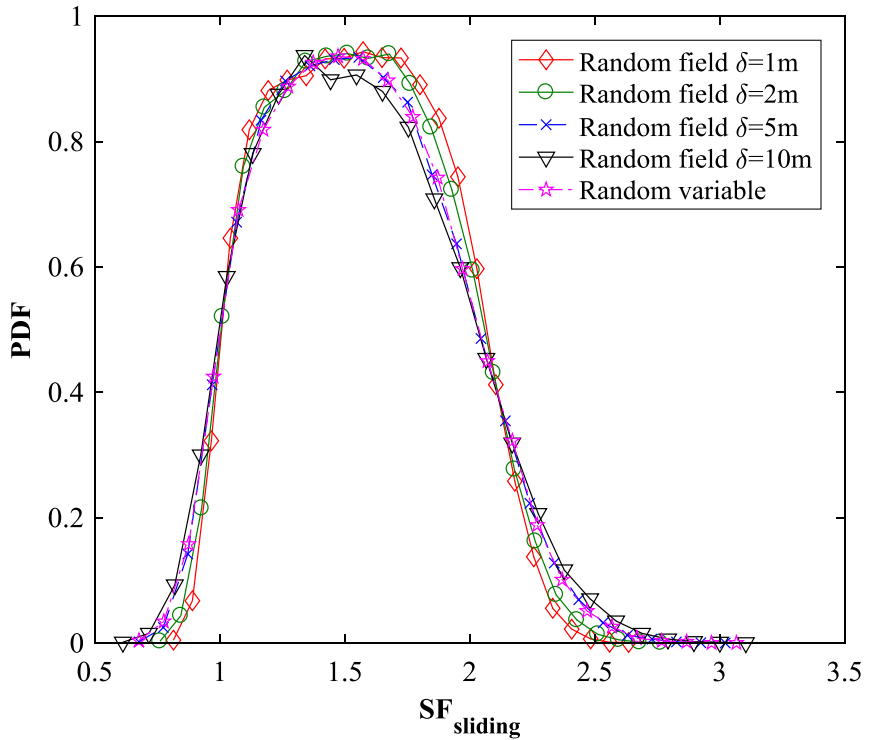

(b)

Fig. 24. PDFs of safety factor against sliding obtained from random field and random variable. (a) ordinary load combination. (b) earthquake load combination. 


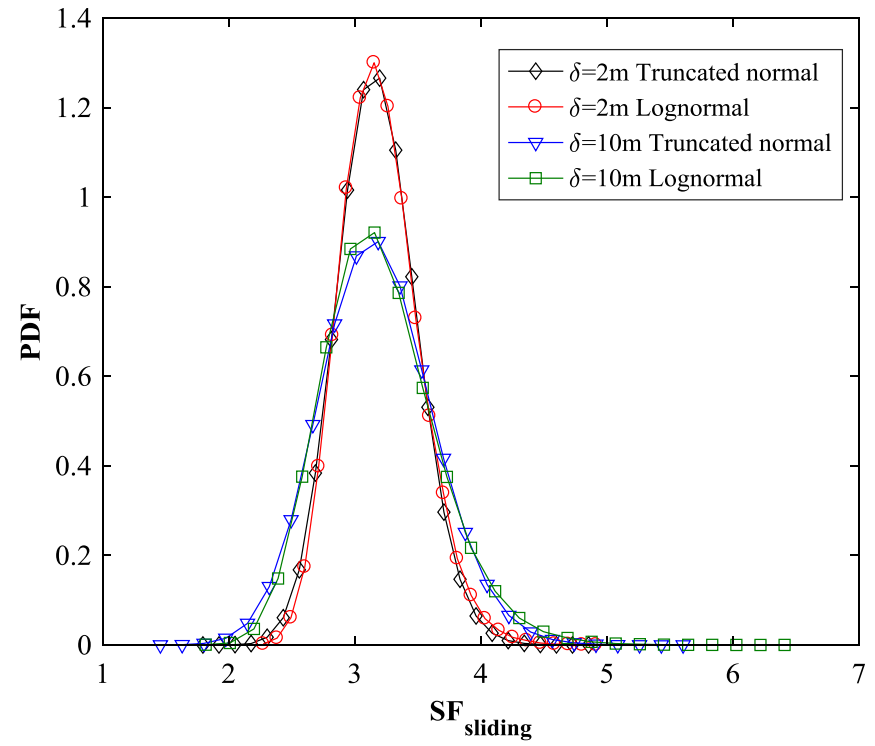

(a)

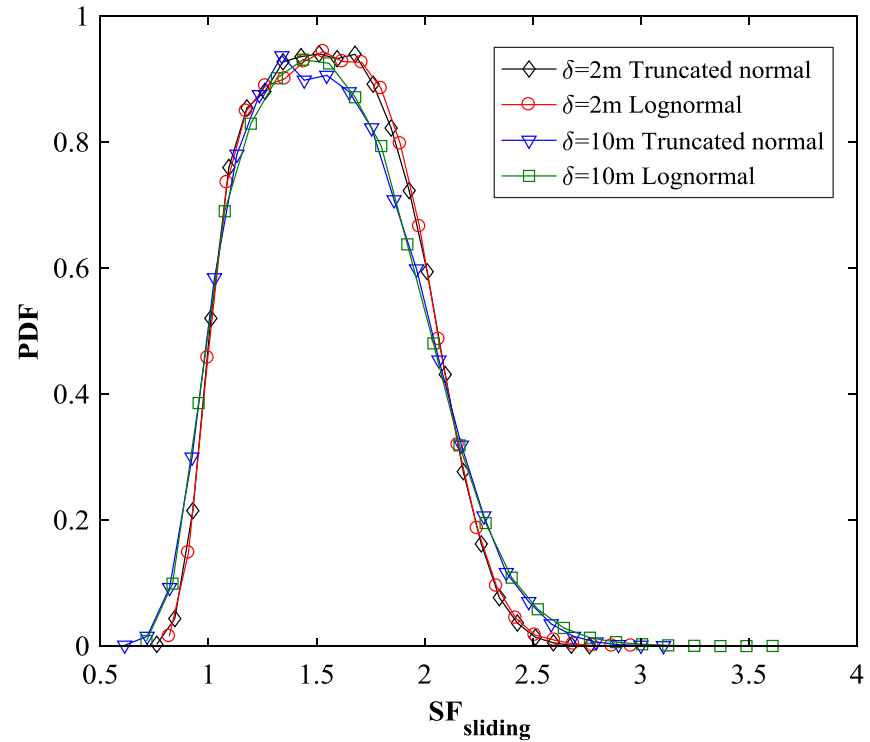

(b)

Fig. 25. PDFs of safety factor against sliding obtained from both truncated normal and lognormal distribution of the input parameters. (a) ordinary load combination. (b) earthquake load combination. 


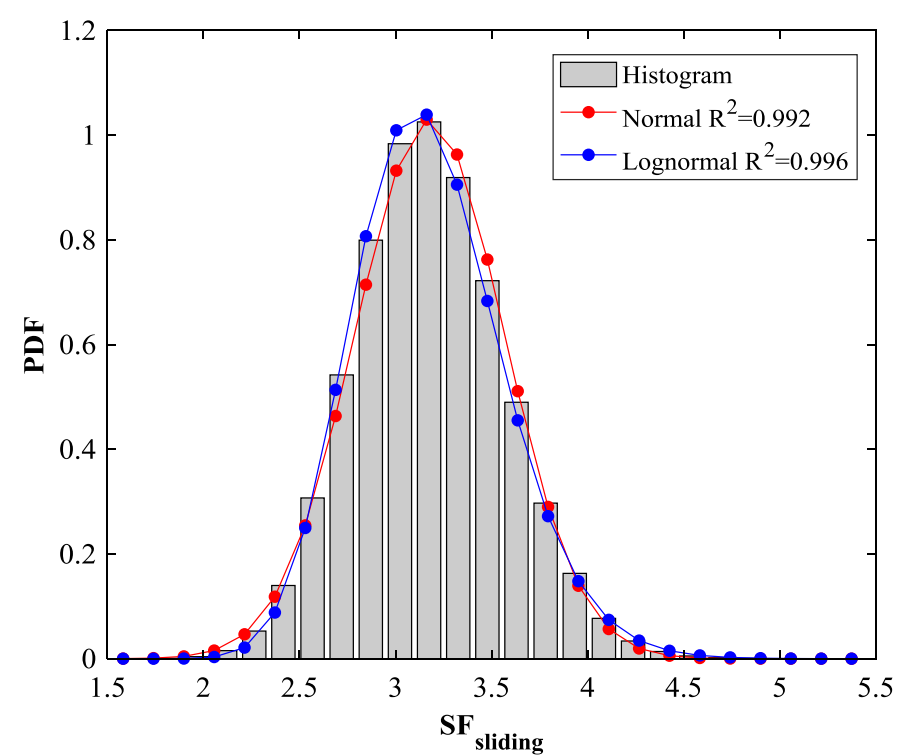

(a)

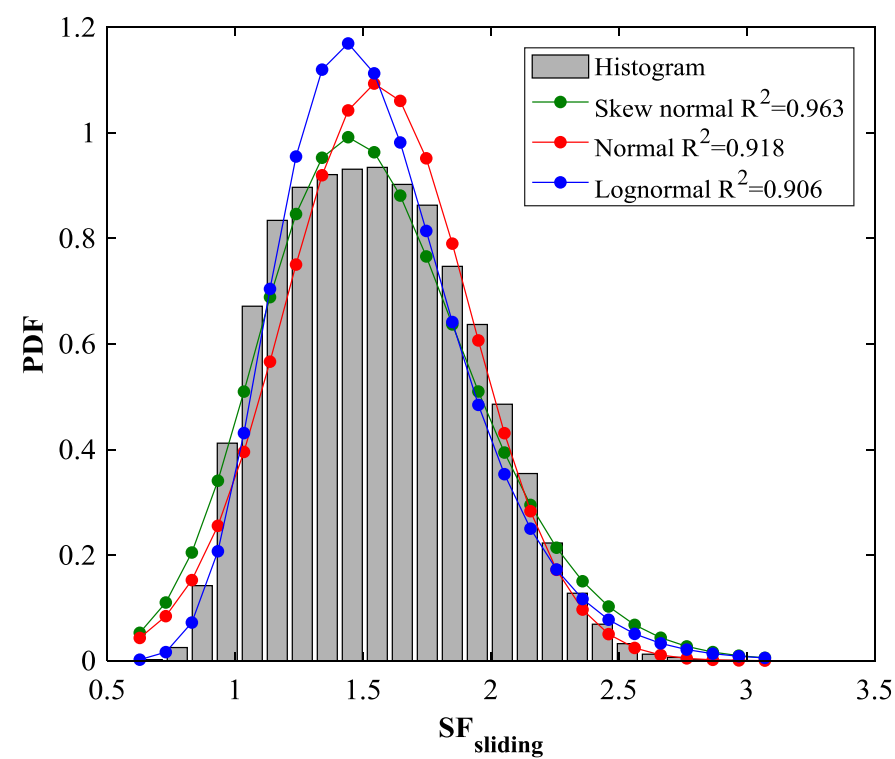

(b)

Fig. 26. Histogram of safety factor against sliding together with distribution fits. (a) ordinary load combination and induced normal and lognormal distributions. (b) earthquake load combination and induced normal, lognormal, and skew normal distributions. 


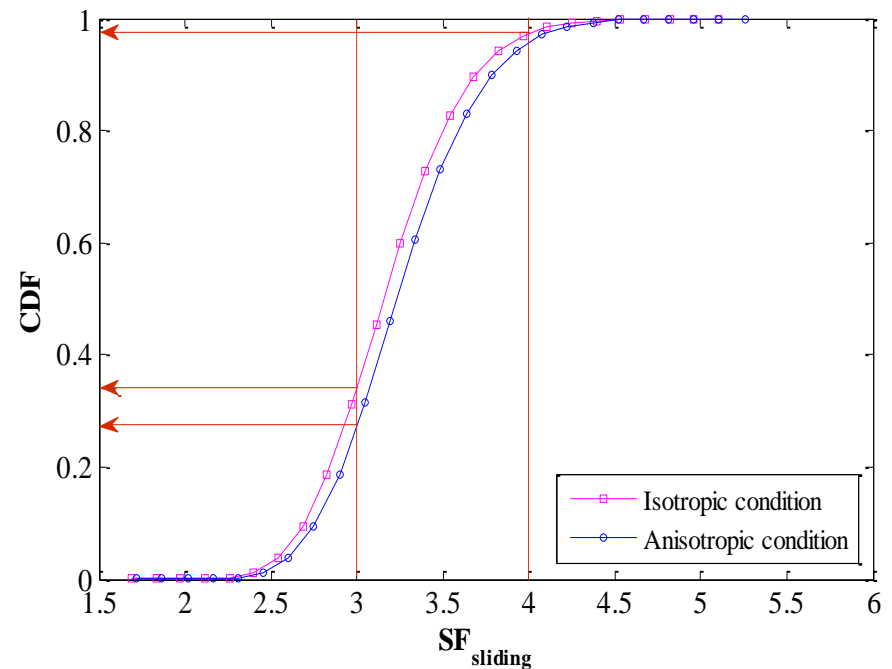

(a)

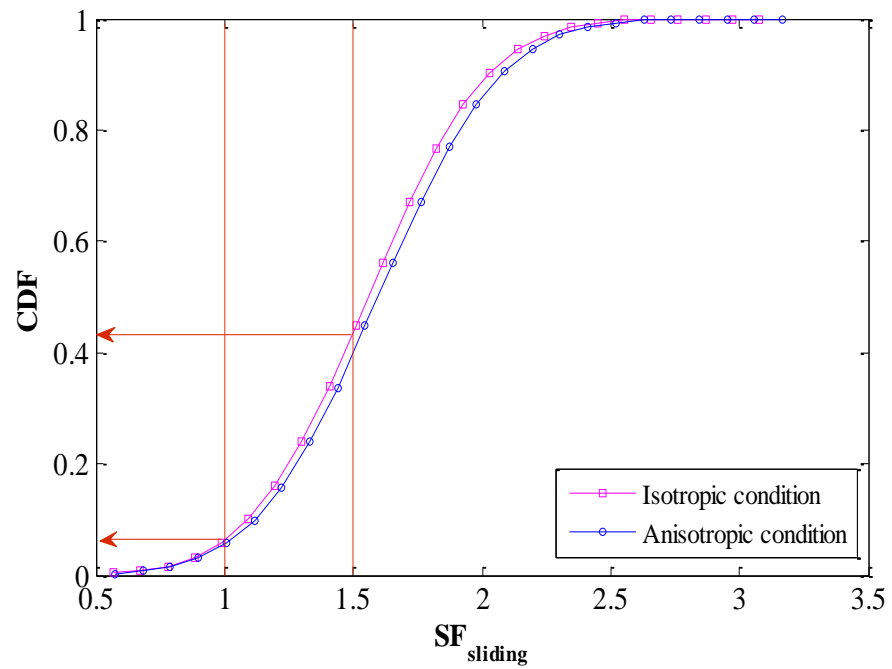

(b)

Fig. 27. CDFs of safety factor against sliding. (a) ordinary load combination. (b) earthquake load combination. 


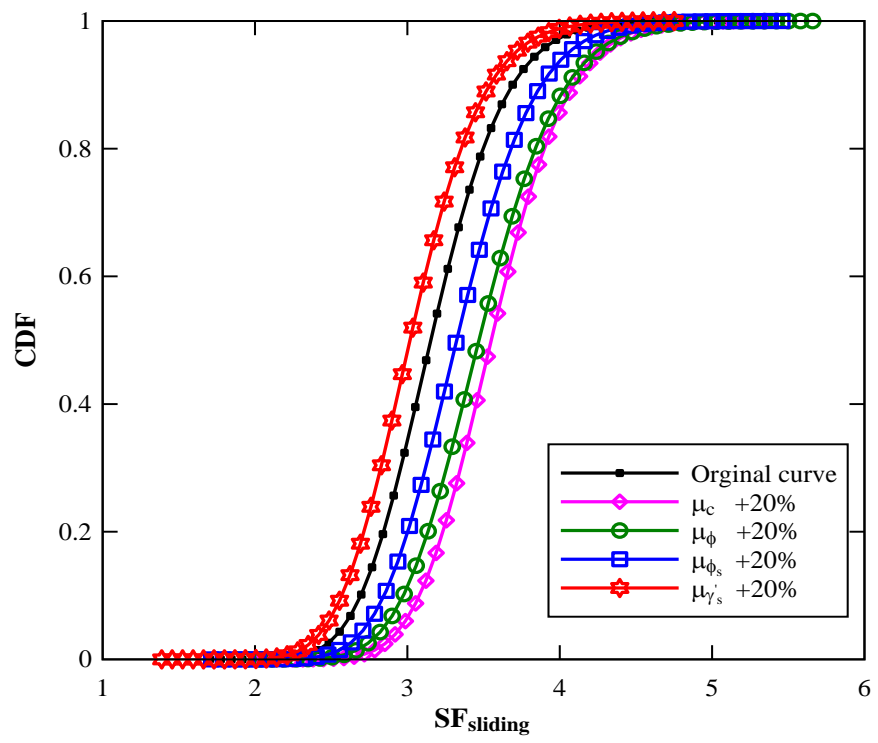

Fig. 28. Sensitivity of CDFs regarding the ordinary load combination.

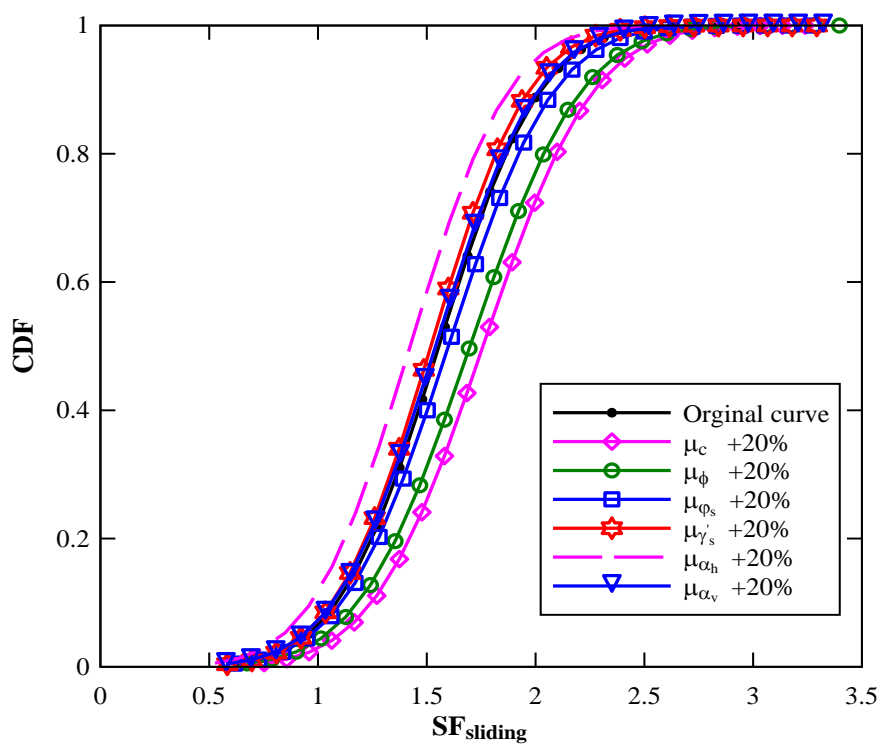

Fig. 29. Sensitivity of CDFs regarding the earthquake load combination. 
Table 1

Deterministic parameters used for stability analysis.

\begin{tabular}{cccccc}
\hline Parameters & $\gamma_{\mathrm{w}}\left(\mathrm{kN} / \mathrm{m}^{3}\right)$ & $\mathrm{A}\left(\mathrm{m}^{2}\right)$ & $\mathrm{H}(\mathrm{m})$ & $\mathrm{W}(\mathrm{kN})$ & $C_{e}$ \\
\hline Value & 9.81 & 15 & 6 & 900 & 0.73 \\
\hline
\end{tabular}

Table 2

Stochastic lognormal parameters used for seepage analysis.

\begin{tabular}{cccc}
\hline Parameters & Mean & $\begin{array}{c}\text { Coefficient of Variation } \\
(\mathrm{COV})\end{array}$ & $\begin{array}{c}\text { Autocorrelation Distance } \\
(\mathrm{m})\end{array}$ \\
\hline $\mathrm{K}_{\mathrm{x}}(\mathrm{m} / \mathrm{s})$ & $10^{-5}$ & $0.125,0.25,0.5,1$ & $1,4,8,20, \infty$ \\
$\mathrm{K}_{\mathrm{z}}(\mathrm{m} / \mathrm{s})$ & $2 \times 10^{-6}$ & $0.125,0.25,0.5,1$ & $1,2,4,8, \infty$ \\
\hline
\end{tabular}

Table 3

Stochastic truncated normal* parameters used for stability analysis.

\begin{tabular}{cccc}
\hline Parameters & Mean & Standard Deviation & $\begin{array}{c}\text { Autocorrelation Distance } \\
(\mathrm{m})\end{array}$ \\
\hline $\mathrm{c}(\mathrm{kPa})$ & 30 & 4 & $1,2,5,10$ \\
$\gamma^{\prime}\left(\mathrm{kN} / \mathrm{m}^{3}\right)$ & 9.5 & 0.25 & - \\
$\phi($ Degree $)$ & 30 & 5 & $1,2,5,10$ \\
$\gamma_{\mathrm{s}}^{\prime}\left(\mathrm{kN} / \mathrm{m}^{3}\right)$ & 8.7 & 0.25 & - \\
$\phi_{\mathrm{s}}($ Degree $)$ & 30 & 5 & - \\
\hline
\end{tabular}

* In the truncated distribution, the mean plus or minus four standard deviations was selected to cover 99.994 percent of data.

Table 4

Stochastic truncated exponential parameters used for stability analysis.

\begin{tabular}{ccccc}
\hline Parameters & Mean & Standard Deviation & Maximum & Minimum \\
\hline$\alpha_{\mathrm{h}}$ & 0.2062 & 0.0798 & 0.1 & 0.4 \\
$\alpha_{\mathrm{v}}$ & 0.06873 & 0.0226 & 0.033 & 0.133 \\
\hline
\end{tabular}


Table 5

Comparison of seepage flow rate $(\mathrm{Q})$ obtained for all cutoff wall configurations.

\begin{tabular}{lllll}
\hline Method & Configuration 1 & Configuration 2 & Configuration 3 & Configuration 4 \\
\hline Presented program & $2.1686 \times 10^{-5}\left(\mathrm{~m}^{3} / \mathrm{s}\right)$ & $2.3258 \times 10^{-5}\left(\mathrm{~m}^{3} / \mathrm{s}\right)$ & $2.3180 \times 10^{-5}\left(\mathrm{~m}^{3} / \mathrm{s}\right)$ & $2.3174 \times 10^{-5}\left(\mathrm{~m}^{3} / \mathrm{s}\right)$ \\
SEEP/W & $2.1685 \times 10^{-5}\left(\mathrm{~m}^{3} / \mathrm{s}\right)$ & $2.3258 \times 10^{-5}\left(\mathrm{~m}^{3} / \mathrm{s}\right)$ & $2.3179 \times 10^{-5}\left(\mathrm{~m}^{3} / \mathrm{s}\right)$ & $2.3172 \times 10^{-5}\left(\mathrm{~m}^{3} / \mathrm{s}\right)$ \\
\hline
\end{tabular}

\section{Table 6}

Comparison results of random field and random variable for sliding stability under ordinary load condition.

\begin{tabular}{cccccc}
\hline \multirow{2}{*}{ Methods } & $\begin{array}{c}\text { Autocorrelation } \\
\text { Distance }\end{array}$ & Mean of SF & $\begin{array}{c}\text { Standard Deviation of } \\
\text { SF }\end{array}$ & $\beta$ & $\mathrm{P}_{\mathrm{f}}(\%)$ \\
\hline \multirow{3}{*}{ Random field } & $1 \mathrm{~m}$ & 3.178 & 0.262 & 8.320 & $\approx 0$ \\
& $2 \mathrm{~m}$ & 3.178 & 0.310 & 7.019 & $1.1 \mathrm{e}-10$ \\
& $5 \mathrm{~m}$ & 3.178 & 0.387 & 5.625 & $9.2 \mathrm{e}-07$ \\
Random variable & $10 \mathrm{~m}$ & 3.179 & 0.442 & 4.936 & $3.9 \mathrm{e}-05$ \\
\hline
\end{tabular}

Table 7

Comparison results of random field and random variable for sliding stability under earthquake load condition.

\begin{tabular}{cccccc}
\hline Methods & $\begin{array}{c}\text { Autocorrelation } \\
\text { Distance }\end{array}$ & Mean of SF & Standard Deviation of & $\beta$ & $\mathrm{P}_{\mathrm{f}}(\%)$ \\
\hline \multirow{3}{*}{ Random field } & $1 \mathrm{~m}$ & 1.557 & 0.336 & 1.656 & 4.890 \\
& $2 \mathrm{~m}$ & 1.556 & 0.346 & 1.609 & 5.380 \\
& $5 \mathrm{~m}$ & 1.555 & 0.365 & 1.522 & 6.400 \\
Random variable & $10 \mathrm{~m}$ & 1.557 & 0.380 & 1.466 & 7.140 \\
& - & 1.556 & 0.365 & 1.523 & 6.390 \\
\hline
\end{tabular}

Table 8

Constant of PDF for the safety factor against sliding under earthquake load combination.

\begin{tabular}{ccccc}
\hline Distribution & Mean & Standard Deviation & Skewness & $\mathrm{R}^{2}$ \\
\hline Normal & 1.508 & 0.406 & - & 0.918 \\
Lognormal & 1.588 & 0.442 & - & 0.906 \\
Skew normal & 1.542 & 0.416 & 0.402 & 0.963 \\
\hline
\end{tabular}




\section{References}

[1] U.S. Bureau of Reclamation, Design of small dams, Water Resources Technical Publication; 1987.

[2] R. Fell, P. MacGregor, D. Stapledon, G. Bell, Geotechnical engineering of dams, CRC Press; 2005.

[3] P. Novak, A.I.B. Moffat, C. Nalluri, R. Narayanan, Hydraulic structures, CRC Press; 2007.

[4] M. Andreini, P. Gardoni, S. Pagliara, M. Sassu, Probabilistic models for erosion parameters and reliability analysis of earth dams and levees, ASCE-ASME Journal of Risk and Uncertainty in Engineering Systems, Part A: Civil Engineering, 2016; 2(4): 04016006.

[5] A. Krounis, F. Johansson, S. Larsson, Effects of spatial variation in cohesion over the concreterock interface on dam sliding stability, Journal of Rock Mechanics and Geotechnical Engineering, 2015; 7(6): 659-667.

[6] M. Foster, R. Fell, M. Spannagle, A method for assessing the relative likelihood of failure of embankment dams by piping, Canadian Geotechnical Journal, 2000; 37(5): 1025-1061.

[7] R. Fell, M. Foster, R. Davidson, J. Cyganiewicz, G. Sills, N. Vroman, A unified method for estimating probabilities of failure of embankment dams by internal erosion and piping, UNICIV Report R 446; 2008.

[8] C.F. Wan, R. Fell, Investigation of rate of erosion of soils in embankment dams, Journal of geotechnical and geoenvironmental engineering, 2004; 130(4): 373-380.

[9] D.S. Chang, L.M. Zhang, Critical hydraulic gradients of internal erosion under complex stress states, Journal of geotechnical and geoenvironmental engineering, 2012; 139(9): 1454-1467.

[10] M.S. Fleshman, J.D. Rice, Laboratory modeling of the mechanisms of piping erosion initiation, Journal of geotechnical and geoenvironmental engineering, 2014; 140(6): 04014017.

[11] B. Mansuri, F. Salmasi, B. Oghati, Effect of location and angle of cutoff wall on uplift pressure in diversion dam, Geotechnical and Geological Engineering, 2014; 32(5): 1165-1173.

[12] G.L. Asawa, Irrigation and water resources engineering, New Age International; 2006. 
[13] A.J. Li, A.V. Lyamin, R.S. Merifield, Seismic rock slope stability charts based on limit analysis methods, Computers and Geotechnics, 2009; 36(1): 135-148.

[14] D.V. Griffiths, J. Huang, G.A. Fenton, Influence of spatial variability on slope reliability using 2D random fields, Journal of geotechnical and geoenvironmental engineering, 2009; 135(10): 13671378.

[15] G. Wang, Z. Ma, Application of probabilistic method to stability analysis of gravity dam foundation over multiple sliding planes, Mathematical Problems in Engineering, 2016; 2016: 4264627.

[16] D.V. Griffiths, J. Huang, G.A. Fenton, Probabilistic infinite slope analysis, Computers and Geotechnics, 2011; 38 (4): 577-584.

[17] M.K. Lo, Y.F. Leung, Probabilistic Analyses of Slopes and Footings with Spatially Variable Soils Considering Cross-Correlation and Conditioned Random Field, Journal of geotechnical and geoenvironmental engineering, 2017; 143(9): 04017044.

[18] J. Ji, C. Zhang, Y. Gao, J. Kodikara, Effect of 2D spatial variability on slope reliability: A simplified FORM analysis. Geoscience Frontiers, 2017.

[19] J. Ji, J.K. Kodikara, Efficient reliability method for implicit limit state surface with correlated nonGaussian variables, International Journal for Numerical and Analytical Methods in Geomechanics, 2015; 39(17): 1898-1911.

[20] D.M. Do, W. Gao, C. Song, Stochastic finite element analysis of structures in the presence of multiple imprecise random field parameters, Computer methods in applied mechanics and engineering, 2016; 300: 657-688.

[21] D.V. Griffiths, G.A. Fenton, Seepage beneath water retaining structures founded on spatially random soil, Geotechnique, 1993; 43(4): 577-87.

[22] S.E. Cho, Probabilistic analysis of seepage that considers the spatial variability of permeability for an embankment on soil foundation, Engineering Geology, 2012; 133: 30-39. 
[23] X. Tan, X. Wang, S. Khoshnevisan, X. Hou, F. Zha, Seepage analysis of earth dams considering spatial variability of hydraulic parameters, Engineering Geology, 2017; 228: 260-269.

[24] A. Srivastava, G.S. Babu, S. Haldar, Influence of spatial variability of permeability property on steady state seepage flow and slope stability analysis, Engineering Geology, 2010; 110(3): 93-101.

[25] A.A. Ahmed, Stochastic analysis of free surface flow through earth dams, Computers and Geotechnics, 2009; 36(7): 1186-1190.

[26] A.A. Ahmed, Stochastic analysis of seepage under hydraulic structures resting on anisotropic heterogeneous soils, Journal of geotechnical and geoenvironmental engineering, 2012; 139(6): 1001-1004.

[27] D.V. Griffiths, G.A. Fenton, Probabilistic analysis of exit gradients due to steady seepage, Journal of geotechnical and geoenvironmental engineering, 1998; 124(9): 789-797.

[28] G.A. Fenton, D.V. Griffiths, Extreme hydraulic gradient statistics in stochastic earth dam, Journal of geotechnical and geoenvironmental engineering, 1997; 123(11): 995-1000.

[29] D.V. Griffiths, G.A. Fenton, Three-dimensional seepage through spatially random soil, Journal of geotechnical and geoenvironmental engineering, 1997; 123(2): 153-160.

[30] D.Q. Li, S.H. Jiang, Z.J. Cao, W. Zhou, C.B. Zhou, L.M. Zhang, A multiple response-surface method for slope reliability analysis considering spatial variability of soil properties, Engineering Geology, 2015; 187: 60-72.

[31] Z. Cao, Y. Wang, Bayesian model comparison and selection of spatial correlation functions for soil parameters, Structural Safety, 2014; 49: 10-17.

[32] J.N. Reddy, An introduction to the finite element method, McGraw-Hill; 1993.

[33] T. Elkateb, R. Chalaturnyk, P.K. Robertson, An overview of soil heterogeneity: quantification and implications on geotechnical field problems, Canadian Geotechnical Journal, 2003; 40(1): 1-15.

[34] S.E. Cho, Probabilistic stability analysis of rainfall-induced landslides considering spatial variability of permeability, Engineering Geology, 2014; 171: 11-20. 
[35] D.K. Green, Efficient Markov Chain Monte Carlo for combined Subset Simulation and nonlinear finite element analysis, Computer methods in applied mechanics and engineering, 2017; 313 : $337-361$.

[36] A. Johari, S.M. Hosseini, A. Keshavarz, Reliability analysis of seismic bearing capacity of strip footing by stochastic slip lines method, Computers and Geotechnics, 2017; 91: 203-217.

[37] M. Papadrakakis, N.D. Lagaros, Reliability-based structural optimization using neural networks and Monte Carlo simulation, Computer methods in applied mechanics and engineering, 2002; 191(32): 3491-3507.

[38] G.A. Fenton, D.V. Griffiths, Risk assessment in geotechnical engineering, John Wiley \& Sons; 2008.

[39] Y. Wang, Z. Cao, S.K. Au, Efficient Monte Carlo simulation of parameter sensitivity in probabilistic slope stability analysis, Computers and Geotechnics, 2010; 37(7): 1015-1022.

[40] D.Q. Li, F.P. Zhang, Z.J. Cao, W. Zhou, K.K. Phoon, C.B. Zhou, Efficient reliability updating of slope stability by reweighting failure samples generated by Monte Carlo simulation, Computers and Geotechnics, 2015; 69: 588-600.

[41] L.L. Liu, Y.M. Cheng, Efficient system reliability analysis of soil slopes using multivariate adaptive regression splines-based Monte Carlo simulation, Computers and Geotechnics, 2016; 79: 41-54.

[42] G.B. Baecher, J.T. Christian, Reliability and statistics in geotechnical engineering, John Wiley \& Sons; 2005.

[43] F. Kang, S. Han, R. Salgado, J. Li, System probabilistic stability analysis of soil slopes using Gaussian process regression with Latin hypercube sampling, Computers and Geotechnics, 2015; 63: $13-25$.

[44] J. Huang, D.V. Griffiths, G.A. Fenton, System reliability of slopes by RFEM, Soils and Foundations, 2010; 50(3): 343-353. 
[45] J. Ji, H.J. Liao, B.K. Low, Modeling 2-D spatial variation in slope reliability analysis using interpolated autocorrelations, Computers and Geotechnics, 2012; 40: 135-146.

[46] J. Ji, A simplified approach for modeling spatial variability of undrained shear strength in out-plane failure mode of earth embankment, Engineering Geology, 2014; 183: 315-323.

[47] A. Noorzad, M. Rohaninejad, Reliability analysis of piping in embankment dam, Numerical Methods in Geotechnical Engineering, 2010; (2010): 375-381.

[48] A. Johari, A.M. Lari, A.M., System probabilistic model of rock slope stability considering correlated failure modes, Computers and Geotechnics, 2017; 81: 26-38.

[49] L.L. Liu, Y.M. Cheng, Efficient system reliability analysis of soil slopes using multivariate adaptive regression splines-based Monte Carlo simulation, Computers and Geotechnics, 2016; 79: 41-54.

[50] D.V. Griffiths, G.A. Fenton, Probabilistic settlement analysis by stochastic and random finiteelement methods, Journal of geotechnical and geoenvironmental engineering, 2009; 135(11): 16291637.

[51] A. Azzalini, A. Capitanio, Statistical applications of the multivariate skew normal distribution, Journal of the Royal Statistical Society, 1999; 61(3): 579-602.

[52] S.K. Ashour, M.A. Abdel-hameed, Approximate skew normal distribution, Journal of Advanced Research, 2010; 1(4): 341-350. 
